TITLE:

\title{
Dysfunction of lipid sensor GPR120 leads to obesity in both mouse and human.
}

\author{
AUTHOR(S): \\ Ichimura, Atsuhiko; Hirasawa, Akira; Poulain-Godefroy, Odile; \\ Bonnefond, Amélie; Hara, Takafumi; Yengo, Loïc; Kimura, Ikuo; ... \\ Wolowczuk, Isabelle; Tsujimoto, Gozoh; Froguel, Philippe
}

\section{CITATION:}

Ichimura, Atsuhiko ...[et al]. Dysfunction of lipid sensor GPR120 leads to obesity in both mouse and human.. Nature 2012

\section{ISSUE DATE:}

2012-02-19

\section{URL:}

http://hdl.handle.net/2433/153278

\section{RIGHT:}

(C)2012 Macmillan Publishers Limited. All rights reserved; 許諾条件によ り本文は2012-08-19に公開.; この論文は出版社版でありません。引用 の際には出版社版をご確認ご利用ください。; This is not the published version. Please cite only the published version. 


\section{Dysfunction of lipid sensor GPR120 leads to obesity in both mouse and human}

Atsuhiko Ichimura $^{1 *}$, Akira Hirasawa ${ }^{1 *}$, Odile Poulain-Godefroy ${ }^{2,3 *}$, Amélie Bonnefond $^{2,3} *$, Takafumi Hara ${ }^{1}$, Loïc Yengo ${ }^{2,3}$, Ikuo Kimura ${ }^{1}$, Audrey Leloire ${ }^{2,3}$, Ning Liu $^{1}$, Keiko Iida ${ }^{1}$, Hélène Choquet ${ }^{2,3}$, Philippe Besnard ${ }^{4}$, Cécile Lecoeur ${ }^{2,3}$, Sidonie Vivequin $^{2,3}$, Kumiko Ayukawa ${ }^{1}$, Masato Takeuchi ${ }^{1}$, Kentaro Ozawa ${ }^{1}$, Maithé Tauber ${ }^{5}$, Claudio Maffeis ${ }^{6,7}$, Anita Morandi ${ }^{2,3,6}$, Raffaella Buzzetti ${ }^{8}$, Paul Elliott ${ }^{9}$, Anneli Pouta $^{10,11}$, Marjo-Riitta Jarvelin ${ }^{9,10,12}$, Antje Körner $^{13}$, Wieland Kiess ${ }^{13}$, Marie Pigeyre $^{14,15}$, Roberto Caiazzo ${ }^{14,16}$, Wim Van Hul ${ }^{17}$, Luc Van Gaal ${ }^{18}$, Fritz Horber ${ }^{19}$, Beverley Balkau ${ }^{20,21}$, Claire Lévy-Marchal ${ }^{22}$, Konstantinos Rouskas ${ }^{2,3,23}$, Anastasia Kouvatsi $^{23}$, Johannes Hebebrand ${ }^{24}$, Anke Hinney ${ }^{24}$, Andre Scherag ${ }^{25}$, François Pattou $^{14,16}$, David Meyre ${ }^{2,3,26}$, Taka-aki Koshimizu27, Isabelle Wolowczuk ${ }^{2,3}$, Gozoh Tsujimoto $^{1 \#}$, Philippe Froguel ${ }^{2,3,28 \#}$

${ }^{1}$ Department of Genomic Drug Discovery Science, Graduate School of Pharmaceutical Sciences, Kyoto University, 46-29 Yoshida Shimoadachi-cho, Sakyo-ku, Kyoto 606-8501, Japan; ${ }^{2}$ Centre National de la Recherche Scientifique (CNRS)-Unité mixte de recherche (UMR) 8199, Lille Pasteur Institute, Lille 59000, France; ${ }^{3}$ Lille Nord de France University, Lille 59000, France; ${ }^{4}$ Institut National de la Santé et de la Recherche Médicale (Inserm)-UMR U866, Physiologie de la Nutrition, Bourgogne University, AgroSup Dijon, Dijon 21078, France; ${ }^{5}$ Inserm-U563, Children's Hospital, Centre Hospitalier Universitaire, Toulouse 31000, France; ${ }^{6}$ Regional Centre for Juvenile Diabetes, Obesity and Clinical Nutrition, Verona 37134, Italy; ${ }^{7}$ Department of Mother and Child, Biology-Genetics, Section of Paediatrics, University of Verona, Verona 37134, Italy; ${ }^{8}$ Department of Clinical Sciences, La Sapienza University, Rome 00161, Italy; ${ }^{9}$ Medical Research Council-HPA Centre for Environment and Health, Department of Epidemiology and Biostatistics, School of Public Health, St Mary's campus, Imperial College London, London W2 1PG, UK; ${ }^{10}$ National Public Health Institute, Biocenter Oulu, University of Oulu, Oulu 90220, Finland; ${ }^{11}$ Institute of Clinical Medicine/Obstetrics and Gynecology, University of Oulu, Oulu 90220, Finland; ${ }^{12}$ Institute of Health Sciences, University of Oulu, Oulu 90220, Finland; ${ }^{13}$ Center for Pediatric Research, Department of Women's \& Child Health, University of Leipzig, Leipzig 04317, Germany; ${ }^{14}$ Inserm-U859, Lille Nord de France University, Lille 59000, France; ${ }^{15}$ Lille University Hospital, Nutrition, Lille 59000, France; ${ }^{16}$ Lille University Hospital, Endocrine Surgery, Lille 59000, France; ${ }^{17}$ Department of Medical Genetics, University of Antwerp, Antwerp 2610, Belgium; ${ }^{18}$ Department of Endocrinology, Antwerp University Hospital, Antwerp 2650, Belgium; ${ }^{19}$ Department of Surgery and Internal Medicine, Clinic Lindberg, Medical Department, Winterthur 8400, and University of Berne, Berne 3011, Switzerland; ${ }^{20}$ Inserm-U780, Centre for research in Epidemiology and Population Health (CRESP), Villejuif 94800, France; ${ }^{21}$ Paris-Sud 11 University, Orsay 91405, France; ${ }^{22}$ Inserm-U690, Robert Debré hospital, Paris 75935, France; ${ }^{23}$ Department of Genetics, Development and Molecular Biology, School of Biology, Aristotle University of Thessaloniki, Thessaloniki 541 24, Greece; ${ }^{24}$ Department of Child and Adolescent Psychiatry, University of Duisburg-Essen, Essen 45147, Germany; ${ }^{25}$ Institute for Medical Informatics, Biometry and Epidemiology, University of Duisburg-Essen, Essen 45122, Germany; ${ }^{26}$ McMaster University, Hamilton L8S4L8, Canada; ${ }^{27}$ Department of Pharmacology, Division of Molecular Pharmacology, Jichi Medical University, Tochigi 329-0498, Japan; ${ }^{28}$ Department of Genomics of Common Disease, School of Public Health, Imperial College London, Hammersmith Hospital, London W12 0NN, UK.

* These authors contributed equally to this work.

* Address correspondence to: 
- Philippe Froguel, M.D., Ph.D., Section of Genomic Medicine, Hammersmith Hospital, Room E303 Burlington-Danes building Hammersmith Hospital, Imperial College London, Du Cane Road, London W12 0NN, UK. Tel: 44 (0)777 3777 132, Fax: 44 (0)207 594 6543; Email: p.froguel@imperial.ac.uk;

- Gozoh Tsujimoto, M.D., Ph.D., Department of Genomic Drug Discovery Science, Graduate School of Pharmaceutical Sciences, Kyoto University, 46-29 Yoshida Shimoadachi-cho Sakyo-ku, Kyoto 606-8501, Japan. Tel: 81-75-753-4523, Fax: 81-75-753-4544; E-mail: gtsuji@pharm.kyoto-u.ac.jp. 


\section{SUMMARY}

Free fatty acids (FFAs) provide an important energy source as nutrients, and also act as signaling molecules in various cellular processes ${ }^{1-4}$. Several G-protein-coupled receptors have been identified as FFAs receptors which play significant roles in physiology as well as in several diseases ${ }^{3,5-13}$. GPR120 functions as a receptor for unsaturated long-chain free fatty acids and plays a critical role in various physiologic homeostasis mechanisms such as adipogenesis, regulation of appetite or food preference ${ }^{5,6,14-16}$. Here, we show that high-fat diet (HFD)-fed GPR120-deficient mice develop obesity, glucose intolerance and fatty liver with decreased adipocyte differentiation and lipogenesis and enhanced hepatic lipogenesis. Insulin resistance of HFD-fed GPR120-deficient mice is associated with reduced insulin signaling and enhanced inflammation in adipose tissue. In human, we show that GPR120 expression in adipose tissue is significantly higher in obese individuals than in lean controls. GPR120 exons sequencing in obese subjects reveals a deleterious non-synonymous mutation (p.R270H) which inhibits the GPR120 signaling activity. Furthermore, the p.R270H variant increases risk for obesity in European populations. Overall, this study demonstrates that the lipid sensor GPR120 has a key role in dietary fat-sensing and, thereby, in the control of energy balance in both humans and rodents.

In order to investigate the role of GPR120 in metabolism, we examined GPR120-deficient mice (Supplementary Fig.1) with respect to lipogenesis, glucose and energy homeostasis. Under normal diet (ND) containing 13\% fat, the body weight was similar in both GPR120-deficient and wild-type (WT) mice. However, when 5 weeks-old GPR120-deficient mice were fed a high-fat diet (HFD) containing 60\% fat, their body weight increase was $~ 10 \%$ higher than that of WT mice on HFD (Fig.1a). Difference in HFD-induced body weight gain between WT and GPR120-deficient mice was marked at $~ 8-10$ weeks old and reached a plateau at 13 weeks old. To assess energy expenditure and substrate utilization, we next performed indirect calorimetry on WT and mutant mice on HFD at 9-10 weeks old (Fig.1b) and 15-16 weeks old (Supplementary Fig.2a). The young GPR120-deficient mice showed decreased energy expenditure compared with the young WT mice, particularly during the light/inactive 
phase (Fig.1b left panel), while older mutant and WT mice showed no such a difference (Supplementary Fig.2a left panel). The difference in energy expenditure between GPR120-deficient and WT mice was observed only in the light phase, indicating that lack of the GPR120 receptor primarily affects basal metabolism especially in young mice. The decreased energy expenditure might explain the difference we found in body weight gain between HFD-fed WT and mutant young mice. The lower respiratory quotient (RQ) values in mutant mice could be due to insufficient glucose utility probably because of the decreased insulin sensitivity. In all experiments, both groups of mice showed similar levels of locomotor activity (data not shown). White adipose tissue (WAT) and liver were substantially heavier in HFD-fed GPR120-deficient mice (Supplementary Fig.2b). Plasma low- and high-density lipoprotein cholesterols were significantly higher in HFD-fed GPR120-deficient mice, along with substantially elevated serum alanine aminotransferase levels, indicating abnormal cholesterol metabolism and liver function (Supplementary Table1). Micro-computed tomography scanning revealed that 16 weeks-old GPR120-deficient mice stored much more fat than WT (Fig.1c). A significant increase in adipocyte size in both epididymal (Fig.1d) and subcutaneous (Supplementary Fig.2c) fat was observed in GPR120-deficient mice. Furthermore, the expression of macrophage marker genes (Cd11b, Cd68 and F4/80) and the number of F4/80 positive cells were markedly enhanced in epididymal tissue from HFD-fed GPR120-deficient mice (Fig.1e,f). Moreover, these mice exhibited liver steatosis and hepatic triglycerides (TG) content was markedly increased (Fig.1g). Overall, HFD-induced obesity and fatty livers were more severe in GPR120-deficient mice than in WT mice.

Obesity-associated insulin resistance was also more severe in GPR120-deficient mice. HFD-fed GPR120-deficient mice showed higher levels of fasting plasma glucose and insulin than WT, although these parameters were similar between the two groups under ND (Fig.2a). HFD-induced insulin resistance, as determined by an insulin tolerance test (ITT), was more prominent in GPR120-deficient mice than in WT (Fig.2b left, Supplementary Fig.3a,b). A glucose tolerance test (GTT) further revealed that these mice suffered from impaired glucose metabolism (Fig.2b right, Supplementary Fig.3a,b). The level of plasma leptin was significantly higher in HFD-fed GPR120-deficient mice than in WT mice (Supplementary Fig.3c). However, there was no significant difference in terms of plasma adiponectin level, or 
food intake, between the two groups (Supplementary Fig.3d,e). HFD-fed GPR120-deficient mice showed a marked increase in the size of islets and Ki67 positive cells, suggesting adaptive enlargement of the b-cell mass in response to insulin resistance $^{17,18}$ (Supplementary Fig.3f,g). Moreover, we observed markedly reduced peripheral insulin sensitivity in tissues from HFD-fed GPR120-deficient mice (Fig.2c). Insulin was shown to induce the phosphorylation of Akt (on Ser473) in WAT, liver and skeletal muscle, with similar intensities in ND-fed WT and GPR120-deficient mice (Supplementary Fig.3h). Consistent with the insulin resistance reported above, HFD-fed GPR120-deficient mice exhibited loss of insulin-induced Akt phosphorylation in WAT and the liver.

In order to determine the molecular basis of the metabolic changes in WAT and livers of GPR120-deficient mice, we performed gene expression analyses. We identified approximately 700 differentially expressed genes in WAT between HFD-fed GPR120-deficient and WT mice (Supplementary Fig.4a). Connectivity mapping of these genes showed that pathways relating to insulin signaling and adipocyte differentiation were depressed, while those related to inflammation were enhanced in HFD-fed GPR120-deficient mice (Supplementary Fig.4b). Quantitative real-time PCR (qRT-PCR) analysis confirmed the down-regulation of insulin signaling-related genes (Insr, Irs1, Irs2), adipocyte differentiation marker gene (Fabp4), and lipogenesis-related gene (Scd1) in the epididymal fat from HFD-fed GPR120-deficient mice (Fig.2d, Supplementary Fig.3i). We identified approximately 100 differentially expressed genes in the liver between HFD-fed GPR120-deficient and WT mice (Supplementary Fig.5). Notably, lipogenesis-related genes ( $S c d 1$ and $M e 1$ ), and a fatty acid transporter gene (Cd36), were significantly up-regulated in livers from GPR120-deficient mice. Quantitative RT-PCR analysis confirmed up-regulation of Scd1 in the liver of GPR120-deficient mice (Fig.2d). Western blot analysis confirmed down-regulation of IRb, IRS1, and SCD1 in adipose tissue (Fig.2e), but down-regulation of IRS1 and IRS2 and up-regulation of SCD1 in the livers (Fig.2f) of HFD-fed GPR120-deficient mice. Hence, insulin signaling-related molecules were down-regulated by the lack of GPR120 in both adipose tissue and the liver. However, the expression of SCD1, the rate-limiting enzyme in the biosynthesis of monounsaturated fatty acids, was down-regulated in adipose tissue, but up-regulated in the livers of HFD-fed GPR120-deficient mice. Furthermore, the expression of $S c d 1$ and several adipogenic genes ${ }^{14,19}$ (Pparg, Fabp4 
and Srebf1) was suppressed in mouse embryonic fibroblast (MEF)-derived adipocytes from GPR120-deficient mice, indicating that GPR120 is required for normal adipogenesis, as previously reported in differentiating 3T3-L1 adipocytes depleted of endogenous GPR120 by siRNA ${ }^{14}$ (Fig.2g,h).

To determine the effects of altered lipogenesis upon lipid composition in GPR120-deficient mice, we performed lipidomics analysis in WAT, livers and plasma. Significant changes of major lipid clusters were observed (Supplementary Fig.6). Notably, the hepatic concentration of oleate (C18:1n9c) was significantly higher in HFD-fed GPR120-deficient mice than WT mice. The ratio of C18:1/C18:0, an indicator of SCD1 enzyme activity ${ }^{20-23}$, was markedly enhanced in livers from HFD-fed GPR120-deficient mice than WT (Fig.2i). Moreover, the levels of C16:1n7 palmitoleate, which has been recently recognized as a lipid hormone ${ }^{4}$, in WAT and plasma were significantly lower in HFD-fed GPR120-deficient mice compared with WT (Fig.2j). In particular, lower levels of C16:1n7 palmitoleate were detected even in WAT of ND-fed GPR120-deficient mice (Fig.2j), which appears to be in good accordance with the suppressed Scd1 expression and the reduced SCD1 desaturation index (C16:1/C16:0) ${ }^{20-23}$ (Fig.2k,l). Lipidomics analysis clearly illustrated dysregulated lipogenesis in GPR120-deficient mice, and showed the reduced production of lipid hormone C16:1n7 palmitoleate ${ }^{4}$. Furthermore, to determine whether the enhanced hepatic lipogenesis in GPR120-deficient mice is due to the reduced levels of C16:1n7 palmitoleate, we examined the effect of C16:1n7 palmitoleate treatment on hepatic Scd1 expression. A 6-hour infusion of TG-palmitoleate markedly lowered the enhanced hepatic Scd1 expression in GPR120-deficient mice (Fig.2m). Together, the reduced C16:1n7 palmitoleate may explain the systemic metabolic disorders observed in GPR120-deficient mice on HFD, as palmitoleate has been proposed as a bioactive lipid by which adipose tissue communicates with distant organs (such as liver) and regulates systemic metabolic homeostasis ${ }^{4}$. The present study showed that dysfunction of GPR120 can be underlying mechanism for the diet-associated obesity and obesity-related metabolic disorders in mouse.

The mice data prompted us to assess the potential contribution of GPR120 to the development of obesity and its metabolic complications in humans. First, the expression levels of GPR120 in both subcutaneous (SC) and omental (OM) adipose tissues as well as in liver samples were compared between lean and obese subjects. 
Normoglycemic obese patients and lean individuals ( $n=14$ in each group) were matched for age and gender (Supplementary Table2). As previously described ${ }^{5,14}$, we confirmed that GRP120 is barely expressed in the liver of either lean or obese subjects (data not shown). In contrast, we found that GPR120 is well-expressed in the adipose tissue of lean individuals (Fig.3a). In addition, human obesity is significantly associated with an increase in GPR120 expression in both SC and OM adipose tissues (1.8-fold increase; $P=0.0004$ and $P=0.003$, respectively). We also found that GPR120 expression in SC adipose tissue strongly correlates with that in OM adipose tissue (Spearman analysis, $\mathrm{r}=0.570$ and $P=2.74 \times 10^{-8}$ ), suggesting a systemic regulation of its expression in humans. Furthermore, we found a positive correlation between GPR120 expression in both SC and OM adipose tissues and subjects' plasma LDL concentrations (upon adjustment for age and sex, $\mathrm{r}=0.247$ / $P=0.0115$ and $\mathrm{r}=0.255$ / $P=0.0118$, respectively).

In order to investigate the contribution of the GPR120 gene (also known as O3FAR1) to human obesity, the four GPR120 exons were sequenced in 312 French non-consanguineous extremely obese children and adults (Supplementary Table3). We only identified two non-synonymous variants, p.R270H (MAF 3\%) and p.R67C/rs6186610 (MAF 5\%), and four rare synonymous variants (MAF<1\%) (Table1). The two non-synonymous variants were subsequently genotyped in 6,942 unrelated obese individuals and 7,654 control subjects, all of European origin (Supplementary Table4). By using a logistic regression model adjusted for age and sex, we found that p.R270H associated with obesity under an additive model (OR=1.62 $[1.31 ; 2.00]_{95 \%} ; P=8.00 \times 10^{-6}$; Table1); whereas we only found a trend for association between p.R67C and obesity $(\mathrm{OR}=1.16 \text { [1.02;1.31 }]_{95 \%} ; P=0.022$; Table1). It is noteworthy that these results were almost the same after adjusting for geographical origin (Table1).

We then genotyped the p.R270H variant in 1,109 French pedigrees selected for obesity $(N=5,045)$ and in 780 German trios with one obese child $(N=2,340)$. We observed a significant over-transmission of the p.R270H low-frequency variant to obese offsprings in 117 pedigrees/trios where the p.R270H variant was present (transmission = $62 \%, P=0.009$, Supplementary Table5). This family-based study excludes a hidden population stratification effect as a cause of spurious association.

The functional significance of both p.R67C and p.R270H mutations was assessed in silico by using several softwares: arginine residues at position 67 and 270 
presented a high evolutionary conservation pattern among mammals and the two amino acid substitutions were predicted to be potentially damaging (Supplementary Table6). To examine the influences of the two non-synonymous variants on GPR120 function in vitro, we assessed each receptor ability to mobilize $\left[\mathrm{Ca}^{2+}\right]_{\mathrm{i}}$ in response to the endogenous agonist $\alpha$-linolenic acid (ALA). We found that ALA induced $\left[\mathrm{Ca}^{2+}\right]_{\mathrm{i}}$ responses in T-REx 293 cells expressing either WT or p.R67C receptor in a dose-dependent manner, whereas ALA-induced $\left[\mathrm{Ca}^{2+}\right]_{\mathrm{i}}$ responses in cells expressing p.R270H were significantly lower $\left(P=1.6 \times 10^{-5}\right)$ than those in cells expressing WT at concentrations above 10 $\mu \mathrm{M}$ ALA (Fig.3b). We further examined the functional ability of the mutated receptors to secrete GLP-1 from human intestinal NCI-H716 cells, as this cell line lacks GPR120 expression and it can secrete GLP-1 in a regulated manner ${ }^{5}$. ALA induced secretion of GLP-1 in NCI-H716 cells expressing either WT ( $P=0.004)$ or p.R67C $\left(P=3.2 \times 10^{-5}\right)$ receptor, but not in NCI-H716 expressing p.R270H mutant $(P=0.96)$ (Fig.3c). Efficiency of transfection for each GPR120 variant receptor was confirmed to be almost the same (data not shown). In order to examine the effect of the p.R270H variant on the WT receptor signaling, we analyzed the $\left[\mathrm{Ca}^{2+}\right]_{i}$ dose-response curves after the transfection of an empty vector, WT receptor plasmid, or p.R270H mutated plasmid into T-REx 293 cells expressing WT GPR120. The transfection of the p.R270H mutated plasmid suppressed dose-response curves, and maximal ALA-induced $\left[\mathrm{Ca}^{2+}\right]_{\mathrm{i}}$ response was significantly decreased $(P=0.004$; Fig.3d). Furthermore, to assess the effect more quantitatively, we analyzed $\left[\mathrm{Ca}^{2+}\right]_{i}$ dose-response curves in T-REx 293 cells stably expressing bicistronic WT/WT, WT/p.R270H or p.R270H/WT receptors (Fig.3e upper panel). Almost equal levels of receptor protein expression in each cell line were confirmed by flow cytometry analysis (Fig.3e lower left panel). Compared with cells expressing WT/WT receptor, the $\left[\mathrm{Ca}^{2+}\right]_{i}$ dose-response curves obtained in cells expressing either WT/p.R270H or p.R270H/WT receptor were markedly suppressed, and maximal ALA-induced $\left[\mathrm{Ca}^{2+}\right]_{\mathrm{i}}$ response was significantly decreased $\left(P=1.2 \times 10^{-5}\right.$; Fig.3e lower right panel). These findings suggest that the p.R270H variant which significantly associated with obesity has an inhibitory effect on GPR120. The p.R270H mutant lacks the ability to transduce long-chain FFA signal, contrary to the p.R67C mutant which did not associate with obesity.

In order to analyze whether being a p.R270H variant carrier may impact on GPR120 expression in the adipose tissue, samples from p.R270H carriers versus 
non-carriers obese patients were quantified for GPR120 expression. Two hundred and thirty-eight obese normoglycemic patients from the ABOS cohort were already genotyped for the p.R270H variant. Ten subjects heterozygous for the $\mathrm{p} . \mathrm{R} 270 \mathrm{H}$ variant were matched for age, gender and BMI with ten non carrier (WT) obese normoglycemic patients (Supplementary Table7). The expression of GPR120 was similar between p.R270H carriers and WT subjects, both in subcutaneous and omental adipose tissues (Supplementary Fig.7a) suggesting that the presence of the functionally deleterious mutation has no primary or secondary effect on gene expression in fat depots. The adipogenesis marker PPARG, the lipogenesis-related factor SCD1 and the macrophage marker CD68 were found similarly well-expressed in the adipose tissues of WT and p.R270H carrier patients (Supplementary Fig.7b,c). Nevertheless, the expression of the fatty acid binding protein FABP4 in omental adipose tissue was significantly lower in p.R270H carriers compared to WT individuals (28\% decrease; $P=0.043$ ), (Supplementary Fig.7b).

In conclusion, we provide here for the first time convincing evidence for a role of the lipid sensor GPR120 in obesity in both mice and humans. Given GPR120 role as a physiologic integrator of the environment (especially the fatty diet), these data provide new insight about the molecular mechanisms by which the Westernized diet may contribute to early onset obesity and associated complications including non alcoholic steatohepatitis (NASH). It also brings some understanding of the metabolic effects of the w-3 FAs which are often proposed as food supplements. This may open novel avenues of research for drug development in the treatment of obesity, lipid metabolism abnormalities and liver diseases, since FFA-sensing receptors represent attractive drug targets.

\section{METHODS SUMMARY}

GPR120-deficient mice were generated by deleting Gpr120 exon 1. All animal procedures and euthanasia were reviewed by the local animal care committee approved by local government authorities. Blood analysis, extraction and detection of mRNA and proteins, and immunohistochemical analysis, were performed following standard protocols as described previously ${ }^{5,24-26}$. Details of antibodies, primers and probes are given in the Methods section. The level of significance for the difference between data sets was assessed using the Student's t-test. Analysis of variance followed by Tukey's 
test was used for multiple comparisons.

In human, GPR120 expression in liver and in both OM and SC adipose tissues was assessed by quantitative RT-PCR (Taqman), in lean and obese subjects from the ABOS cohort. The four GPR120 exons were sequenced in 312 French extremely obese subjects following a standard Sanger protocol. The two identified non-synonymous variants (p.R270H and p.R67C/rs6186610) were subsequently genotyped in a large European obesity case-control study $\left(N_{\text {cases }}=6,942 / N_{\text {controls }}=7,654\right)$, by High Resolution Melting (HRM) and TaqMan, respectively. Association between obesity status and each variant was assessed using a logistic regression adjusted for age and gender, and then for age, gender and geography origin, under an additive model. The consequences of both identified non-synonymous variants on GPR120 function $\left(\left[\mathrm{Ca}^{2+}\right]_{\mathrm{i}}\right.$ response and GLP-1 secretion) were assessed in vitro. The human study protocol was approved by the local ethics committee, and participants from all of the studies signed an informed consent form.

\section{METHODS}

Generation and genotyping of GPR120-deficient mice. GPR120-deficient mice on a mixed C57Bl/6 /129 background were generated by homologous recombination. Exon 1 of the Gpr120 gene was replaced with a PGK-neo cassette (Supplementary Fig.1).

Animals. Mice were housed under a $12 \mathrm{hr}$ light-dark cycle and given regular chow, MF (Oriental Yeast Co., Ltd.). For HFD studies, 5-week-old male mice were placed on a $58 Y 1$ diet (PMI Nutrition International) for a total period of 11 weeks. The methods used for animal care and experimental procedures were approved by the Animal Care Committee of Kyoto University.

Indirect calorimetry. Twenty-four hr energy expenditure and respiratory quotient (RQ) were measured by indirect calorimetry, using an open-circuit calorimeter system (MK-5000RQ, Muromachi Kikai Co. Ltd.). RQ is the ratio of the carbon dioxide production to the oxygen consumption $\left(\mathrm{VO}_{2}\right)$. Energy expenditure was calculated as the product of calorific value of oxygen $(3.815+1.232 \times \mathrm{RQ})$ and $\mathrm{VO}_{2}$. Locomotor activity was measured by using an infrared ray passive sensor system (Supermex, Muromachi Kikai Co. Ltd.). 
Histology and immunohistochemistry. Epididymal adipose and pancreatic tissues were fixed in $10 \%$ neutral-buffered formalin, embedded in paraffin, and sectioned at $5 \mathrm{~mm}$. Hematoxylin and eosin (H\&E) staining was performed using standard techniques. In order to measure diameter of adipocytes and area of pancreatic islets, the diameters of 100 cells from five sections from each group were measured using NIH Image software. More than 10 fields were examined, islet area was traced and total islet area was calculated and expressed as the average score. Liver tissues were embedded in OCT compound (Sakura Finetech) and snap-frozen in liquid nitrogen. Tissue sections were stained with oil red O (Sigma-Aldrich) for lipid deposition using standard methods.

Triglyceride (TG) content assay. In order to determine the TG content of liver, tissue was homogenized with 1/2.5/1.25 (vol/vol) $0.5 \mathrm{M}$ acetic acid/methanol/chloroform. The mixture was shaken and 1.25 volumes of chloroform added. The mixture was shaken overnight, and then 1.25 volumes of $0.5 \mathrm{M}$ acetic acid added. After centrifugation at $1,500 \mathrm{~g}$ for $10 \mathrm{~min}$, the organic layer was collected, dried and resuspended in $100 \%$ isopropyl alcohol. Measurements were conducted using TG E-test Wako (Wako).

Glucose tolerance and insulin tolerance tests. Glucose tolerance assays were performed on 24hr-fasted mice. After baseline glucose values were individually established using One Touch Ultra (LifeScan), each mouse was given an intraperitoneal (i.p.) injection of $1.5 \mathrm{mg}$ glucose/g body weight. Insulin tolerance was conducted using the same glucometer. After baseline glucose values were established, mice were given human insulin $(0.75 \mathrm{mU} / \mathrm{g}$ i.p. Sigma-Aldrich). Clearance of plasma glucose was subsequently monitored at 15, 30, 60, 90 and 120min post-injection.

Immunoblot analysis. For insulin stimulation, 5U of insulin (Sigma-Aldrich) was injected via the inferior vena cava. Five minutes later, samples of liver, skeletal muscle or WAT were dissected and immediately frozen in liquid nitrogen. Immunoblot analysis were performed as described previously, ${ }^{5,24}$. Anti-IRS1 (Millipore), anti-IRS2 (Millipore), anti-SCD1 (Santa Cruz Biotechnology), anti-IRb anti-Akt (Cell Signaling 
Technology), anti-pAkt (Cell Signaling Technology) and anti-b-actin (Sigma-Aldrich) antibodies were used as the primary antibody.

Mouse gene expression analysis. Total RNA was extracted from tissue or cells using ISOGEN (Nippon Gene). Quantitative RT-PCR and microarray analysis were performed as described previously ${ }^{24,26}$. Briefly, genome-wide mRNA expression profiles were obtained by microarray analysis with the Affymetrix GeneChip Mouse 4302.0 Array, according to the manufacturer's instructions. We used the robust multi-array analysis (RMA) expression measure that represents the log transformation of intensities (background corrected and normalized) from the GeneChips ${ }^{27}$. Functional associations between differentially expressed genes were analyzed using Ingenuity Pathways Analysis (version 4.0, Ingenuity Systems). The microarray data are available from the Gene Expression Omnibus (GEO, http://www.ncbi.nlm.nih.gov/geo/) with the accession number 32095.

Micro-computed tomography (micro-CT) scanning. Images were obtained using a micro-CT system (SHIMADZU ClairvivoCT) with a high-resolution flat panel detector. The maximum resolution of this modality was less than $40 \mathrm{~mm}$. The measurement condition of the scanner was assumed to be cylindrical field of view (FOV) of the section view of $65.3 \mathrm{~mm}$ and the trans-axial view of $300 \mathrm{~mm}$. The $\mathrm{x}$-ray source was biased at $60 \mathrm{keV}$ with the anode current set to $160 \mathrm{~mA}$. CT images were analyzed with Osirix software.

Fatty acid composition of epididymal WAT, liver and plasma. Esterified and non-esterified fatty acid composition was measured by gas chromatography. Briefly, in order to analyze esterified fatty acid, epididymal adipose tissue (20-25mg), liver (25-30mg), and plasma (100m) samples were snap-frozen in liquid nitrogen and homogenized in $4 \mathrm{ml}$ of $0.5 \mathrm{~N} \mathrm{KOH}-M e t h a n o l$. Samples were then boiled at $100^{\circ} \mathrm{C}$ for 30min to hydrolyze. Total lipids in each sample homogenate were then extracted with hexane, followed by trans-esterification of fatty acids with the boron trifluoride-methanol at $100^{\circ} \mathrm{C}$ for $15 \mathrm{~min}$. Methylated fatty acids were then extracted with hexane and analyzed using a GC-2010AF gas chromatograph (SHIMADZU). For the analysis of non-esterified fatty acid, epididymal adipose tissue (10-15mg), liver 
(10-15mg), and plasma (100m) samples were snap-frozen in liquid nitrogen and homogenized in a mixture of $1.2 \mathrm{ml}$ water, $3 \mathrm{ml}$ methanol and $1.5 \mathrm{ml}$ chloroform. Total lipids in each sample homogenate were extracted with a mixture of $1.2 \mathrm{ml}$ of water and $1.2 \mathrm{ml}$ of chloroform, followed by silylation of fatty acids with N,O-Bis(trimethylsilyl)trifluoroacetamide with $\quad 1 \% \quad$ Trimethylchlorosilane (BSTFA-TMCS) at $100^{\circ} \mathrm{C}$ for $60 \mathrm{~min}$. Silylated fatty acids were then extracted with hexane and analyzed using a GC-2010AF gas chromatograph (SHIMADZU).

Mouse embryonic fibroblast (MEF) adipogenesis assay. In order to prepare MEFs, we minced 13.5-days post-coital mouse embryos and digested them with trypsin. Cells were collected and cultured in modified Eagle's medium (a-MEM; supplemented with $10 \%$ fetal bovine serum (FBS), 50U/ml penicillin and $50 \mathrm{mg} / \mathrm{ml}$ streptomycin). We induced confluent MEFs to undergo adipogenic differentiation by incubating them first for 2 days with $10 \mathrm{mg} / \mathrm{ml}$ insulin, $250 \mathrm{nM}$ dexamethasone and $0.5 \mathrm{mM}$ isobutylmethylxanthine (Sigma-Aldrich). We measured cellular triglyceride content with Triglyceride E-test Wako (Wako).

Lipid Infusion. Intralipid solution with $2 \mathrm{mM}$ triglycerides:palmitoleate was prepared using a previously described protocol ${ }^{4}$. Briefly, lipids were dissolved in a solvent containing 5\% glycerol and $0.72 \%$ phosphocholine in $0.9 \%$ saline and sonicated repeatedly. Lipids stayed in suspension for 1 week and had to be vortexed well before loading the syringe and tubing to prevent clogging. Before lipid infusion, mice were anesthetized, and an indwelling catheter was inserted in the left internal jugular vein. After overnight fasting, lipids were infused at a rate of $500 \mathrm{ml} / \mathrm{kg} / \mathrm{hr}$ for $6 \mathrm{hr}$. At the end of the infusion, tissues were collected.

Statistical analysis of GPR120-deficient mouse study. The level of significance for the difference between data sets was assessed using the Student's $t$-test. Analysis of variance followed by Tukey's test was used for multiple comparisons. Data were expressed as means \pm standard error. $P<0.05$ was considered to be statistically significant.

Human study population. The study protocol was approved by all local ethics 
committees and an informed consent was obtained from each subject before participating in the study, in accordance with the Declaration of Helsinki principles. For children younger than 18 years, an oral consent was obtained and parents provided written informed consent. All subjects were of European origin.

Human gene expression analysis. We used liver, SC and OM adipose tissue samples from the ABOS ('Atlas Biologique de l’Obésité Sévère') cohort (ClinicalGov NCT01129297), a cohort study conducted in the 'Département de Chirurgie Générale et Endocrinienne' (Lille CHRU) ${ }^{28}$. Total RNA was extracted from the tissues using RNeasy protect Mini Kit (QIAGEN) and quantified by absorbance in nm at A260/A280 in a PerkinElmer spectrophotometer. Human GPR120, FABP4, PPARG, CD68 and SCD1 mRNA levels were quantified by reverse transcription reaction followed by real time quantitative RT-PCR. Quantitative assessment of human mRNA expression was performed using TaqMan Gene Expression Assays (Hs01111664_m1: GPR120 and Hs99999905_m1: GAPDH; Hs00609791_m1: FABP4; Hs00234592_m1: PPARG; Hs00154355_m1: CD68; Hs01682761_m1: SCD1; Applied Biosystems) with Applied Biosystems 7900HT Fast Real-Time PCR System. As an internal control for potential housekeeper reference variability, gene transcript levels were normalized to GAPDH reference housekeeper transcript level. The mean of triplicate cycle thresholds (CTs) of the target was normalized to the mean of triplicate CTs of the reference internal housekeeper genes using the formula: $2^{\wedge}\left(\mathrm{CT}_{(G A P D H)}-\mathrm{CT}_{\text {(target) }}\right)$ which yielded a relative target-to-reference transcript concentration value, as a fraction of reference transcript. Samples for which the CT was above 35 were excluded from the analysis.

GPR120 exons sequencing. We sequenced the four GPR120 exons in 312 obese patients including 121 French obese adults and 191 French obese children who were recruited by the CNRS-UMR8199 unit and the Department of Nutrition of Paris Hotel Dieu Hospital. GPR120 (or O3FAR1) is located on human chromosome 10q23.33 and encodes a 377-amino-acid protein (NCBI NM_181745.3 and NP_859529). PCR conditions and primers sequences are available upon request. Fragments were bidirectionally sequenced using the automated 3730xl DNA Analyzer (Applied Biosystems). Electrophoregram reads were assembled and analysed using the Variant 
Reporter software (Applied Biosystems). The location of each variant is displayed by base numbers counting from the ATG-translation initiation codon according to the Human Genome Variation Society nomenclature for the description of sequence variations. The position of mutations was indicated according to the human genome build NCBI36/hg18.

Genotyping of both p.R270H and p.R67C/rs6186610 variants. We genotyped the two non-synonymous variants in 6,942 unrelated obese subjects and in 7,654 control subjects, all of European descent. Genotyped populations are described in Supplementary Table4. The set of obese subjects included: 516 unrelated French obese children who were recruited by the CNRS-UMR8199 unit or Toulouse Children's Hospital $^{29}$; 332 Italian obese children from Verona ${ }^{30}$ or Rome ${ }^{31}$; 170 Finnish obese adolescents from the Northern Finland Birth Cohort 1986 (NFBC1986) cohort $^{32}$; 1,164 unrelated French obese adults from the ABOS cohort ${ }^{28}$ or recruited by the CNRS-UMR8199 unit and the Department of Nutrition of Paris Hotel Dieu Hospital ${ }^{29}$; 2,514 Belgian obese patients from the outpatient obesity clinic at the Antwerp University Hospital ${ }^{33}$; 1,736 Swiss obese subjects which were recruited after gastric surgery in Zurich ${ }^{34}$; and 510 Greek obese subjects recruited in the Hippokration Hospital of Thessaloniki or in the Second Department of Internal Medicine of the Hospital of Alexandroupolis ${ }^{35}$. The set of control subjects included: 422 Italian lean children from Verona ${ }^{30}$; 4,639 Finnish lean adolescents from the NFBC1986 cohort $^{32}$; 1,976 French lean adults from the D.E.S.I.R (Data from the Epidemiological Study on the Insulin Resistance syndrome) prospective study ${ }^{36}$ and from the Haguenau study ${ }^{37}$; 148 Belgian lean subjects from Antwerp Hospital ${ }^{33}$; and 469 Greek lean individuals recruited by medical examination centers of Thessaloniki ${ }^{35}$. The 1,109 French pedigrees selected for obesity have been recruited by the CNRS-UMR8199 ${ }^{38}$, and the 780 German childhood obesity trios have been recruited at the Universities of Marburg and Essen ${ }^{39}$. The p.R270H variant was genotyped using the LightCycler 480 High Resolution Melting (HRM) Master kit (Roche), following the manufacturer's protocol. Genotyping of p.R67C/rs6186610 was performed using a custom TaqMan assay according to the manufacturer's instructions (Applied Biosystems). Allelic discrimination was performed using Applied Biosystems 7900HT Fast Real-Time PCR System and SDS 2.3 software. For both variants, genotype success rate was at least 95\% and no deviation $(P>0.05)$ 
from Hardy-Weinberg equilibrium was observed in any of the examined populations.

Phenotyping. The 90th and 97th BMI percentiles were used as thresholds for childhood overweight and obesity, respectively, according to the recommendations of the European Childhood Obesity Group study in local reference populations ${ }^{40,41}$. Adult subjects were defined as normal $\left(\mathrm{BMI}<25 \mathrm{~kg} / \mathrm{m}^{2}\right)$, overweight $\left(25 \leq \mathrm{BMI}<30 \mathrm{~kg} / \mathrm{m}^{2}\right)$, and obese $\left(\mathrm{BMI} \geq 30 \mathrm{~kg} / \mathrm{m}^{2}\right)$ according to the International Obesity Task Force recommendations.

In silico analysis of both p.R270H and p.R67C variants. Phylogenetic conservation of part of GPR120 containing each non-synonymous variant was assessed using UCSC genome browser (Vertebrate Multiz Alignment \& Conservation), based on a phylogenetic hidden Markov model, phastCons ${ }^{42}$. To predict possible impact of both amino acid substitutions on the structure and function of GPR120, we used several softwares: 1/ PolyPhen (Polymorphism Phenotyping) web-based program ${ }^{43,44}$; 2/ PANTHER (Protein ANalysis THrough Evolutionary Relationships) ${ }^{45}$; 3/ SIFT (Sorting Intolerant From Tolerant) algorithm ${ }^{46}$; 4/ SNAP (Screening for Non-Acceptable Polymorphisms) software ${ }^{47}$; and 5/ PMUT web-based program ${ }^{48}$.

Plasmid construction. FLAG-human GPR120/pcDNA5/FRT/TO plasmid was constructed by ligated GPR120 cDNA into the multicloning site of the mammalian expression vector pcDNA5/FRT/TO (Invitrogen) with the N-terminal FLAG tag. Point mutation for constructing the FLAG-human GPR120 p.R67C/pcDNA5/FRT/TO and FLAG-GPR120 p.R270H/pcDNA5/FRT/TO was carried out using the following primers; p.R67C (sense: 5'-ggtgctggtggcgTgccgacgacgcc-3'; anti-sense: 5'-ggcgtcgtcggcAcgccaccagcacc-3') and p.R270H (sense: 5'-agccaccagatccAcgtgtcccagcaggac-3'; anti-sense: 5'-gtcctgctgggacacgTggatctggtggct-3'). All constructs were confirmed by DNA sequencing.

Cell lines and cell culture. Flp-In T-REx-293 (T-REx 293) cells (Invitrogen) were used to develop inducible and stable cell lines T-REx GPR120 (WT, p.R270H or p.R67C). T-REx 293 cells were routinely cultured in Dulbecco’s modified Eagle’s medium 
(DMEM) (Sigma) supplemented with 10\% FBS, 100 $\mu \mathrm{g} / \mathrm{ml}$ zeocin (Invitrogen), and $10 \mu \mathrm{g} / \mathrm{ml}$ blasticidin S (Funakoshi). T-REx 293 cells were transfected with FLAG-GPR120 (WT, p.R270H or p.R67C)/pcDNA5/FRT/TO using Lipofectamine Reagent (Invitrogen) and selected with DMEM, which had been supplemented with

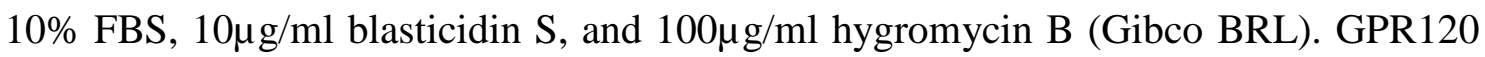
protein expression was induced by adding $10 \mu \mathrm{g} / \mathrm{ml}$ of doxycycline hyclate (Dox) (Sigma) for 48hr. Human NCI-H716 cells were obtained from the American Type Culture Collection (Manassas). Cells were grown in suspension in Roswell Park Memorial Institute (RPMI) 1640 medium supplemented with 10\% FBS, 100IU/ml penicillin, and $100 \mu \mathrm{g} / \mathrm{ml}$ streptomycin.

$\left[\mathrm{Ca}^{2+}\right]_{\mathbf{i}}$ response analysis. Cells were seeded at a density of $2 \times 10^{5}$ cells/well on collagen-coated 96 -well plates, incubated at $37^{\circ} \mathrm{C}$ for $21 \mathrm{hr}$, and then incubated in Hanks' Balanced Salt Solution (HBSS, pH7.4) containing Calcium Assay Kit Component A (Molecular Devices) for $1 \mathrm{hr}$ at room temperature. $\alpha$-Linolenic acid (ALA) used in the fluorometric imaging plate reader (FLIPR, Molecular Devices) assay were dissolved in HBSS containing 1\% DMSO and prepared in another set of 96-well plates. These plates were set on the FLIPR, and mobilization of $\left[\mathrm{Ca}^{2+}\right]_{\mathrm{i}}$ evoked by agonists was monitored.

Transfection. Cells were seeded into $3.5 \mathrm{~cm}$ dish at a density of $1 \times 10^{6}$ cells before transfection. NCI-H716 cells were transfected with $5 \mu \mathrm{g}$ of each plasmid using Lipofectamine 2000 (Invitrogen) according to the manufacturer's protocol. At 24hr post-transfection, transfection of each FLAG-tagged each construct was confirmed by anti-FLAG FACS analysis. Then, the cells were re-seeded in 24-well culture plates coated with Matrigel matrix (BD Biosciences) at a density of approximately $3 \times 10^{5}$ cells per well for the secretion studies. To test the effect of variant receptors on ALA-induced $\left[\mathrm{Ca}^{2+}\right]_{\mathrm{i}}$ response of WT receptor, T-REx 293 cells expressing Dox-inducible FLAG-GPR120 WT were seeded into $15 \mathrm{~cm}$ dish at a density of $2 \times 10^{7}$ cells before transfection. Cells were then transfected with $32 \mu \mathrm{g}$ of each plasmid (empty vector, WT and p.R270H GPR120) using Lipofectamine 2000 (Invitrogen) according to the manufacturer's protocol. At 24hr post-transfection, cells were re-seeded at a density of $2 \times 10^{5}$ cells/well on collagen-coated 96-well plates and treated with $10 \mu \mathrm{g} / \mathrm{ml}$ of Dox, 
then at $48 \mathrm{hr}$ post-transfection ALA-induced $\left[\mathrm{Ca}^{2+}\right]_{\mathrm{i}}$ response was monitored.

GLP-1 secretion analysis. Cells were serum-starved with FBS-free DMEM for 3hr, washed with $\mathrm{HBSS}$, and incubated for $2 \mathrm{hr}$ at $37^{\circ} \mathrm{C}$ in $0.3 \mathrm{ml}$ FBS-free DMEM containing DMSO (negative control), $1 \mu \mathrm{M}$ phorbol 12-myristate 13-acetate (PMA; positive control), or $100 \mu \mathrm{M}$ ALA. Supernatants were collected and active GLP-1 concentration in the supernatant was determined by enzyme immunoassay using GLP-1 (Active) ELISA Kit (Millipore).

\section{Flow cytometry analysis.}

Anti-Flag (Sigma, St. Louis, MO) and anti-HA (Roche, Indianapolis, IN) antibodies were used for staining. Data were acquired and analyzed on FACSCalibur with CellQuest software (Becton Dickinson, Franklin Lakes, New Jersey)

Statistical analysis of human study. We assessed the effect of both non-synonymous variants (p.R270H and p.R67C) on obesity using a logistic regression adjusted for age and gender, and then for age, gender and geography, under an additive model, by using $\mathrm{R}$ software (version 2.12). Adjustment for geography was achieved so as to reflect a North-South gradient between the six different countries of origin of the study participants. An ordinal variable was created and coded: 1 for Finland, 2 for Belgium, $\mathbf{3}$ for France and Switzerland, $\mathbf{4}$ for Italy and $\mathbf{5}$ for Greece. The latter variable was added as a covariate in logistic regression model.

Data analysis for $\left[\mathrm{Ca}^{2+}\right]_{\mathrm{i}}$ response was performed using Igor Pro (WaveMetrics). Significant differences between expression among WT and heterozygous groups, and among lean and obese WT subjects were assessed using non-parametric Mann-Whitney analysis (GraphPad Prism 5 software). 


\section{REFERENCES}

1. Nunez, E.A. Biological complexity is under the 'strange attraction' of non-esterified fatty acids. Prostaglandins Leukot Essent Fatty Acids 57, 107-110 (1997).

2. Haber, E.P., et al. Pleiotropic effects of fatty acids on pancreatic beta-cells. $J$ Cell Physiol 194, 1-12 (2003).

3. Itoh, Y., et al. Free fatty acids regulate insulin secretion from pancreatic beta cells through GPR40. Nature 422, 173-176 (2003).

4. Cao, H., et al. Identification of a lipokine, a lipid hormone linking adipose tissue to systemic metabolism. Cell 134, 933-944 (2008).

5. Hirasawa, A., et al. Free fatty acids regulate gut incretin glucagon-like peptide-1 secretion through GPR120. Nat Med 11, 90-94 (2005).

6. Steneberg, P., Rubins, N., Bartoov-Shifman, R., Walker, M.D. \& Edlund, H. The FFA receptor GPR40 links hyperinsulinemia, hepatic steatosis, and impaired glucose homeostasis in mouse. Cell Metab 1, 245-258 (2005).

7. Wang, J., Wu, X., Simonavicius, N., Tian, H. \& Ling, L. Medium-chain fatty acids as ligands for orphan G protein-coupled receptor GPR84. J Biol Chem 281, 34457-34464 (2006).

8. Ichimura, A., Hirasawa, A., Hara, T. \& Tsujimoto, G. Free fatty acid receptors act as nutrient sensors to regulate energy homeostasis. Prostaglandins Other Lipid Mediat 89, 82-88 (2009).

9. Maslowski, K.M., et al. Regulation of inflammatory responses by gut microbiota and chemoattractant receptor GPR43. Nature 461, 1282-1286 (2009).

10. Ahmed, K., et al. An autocrine lactate loop mediates insulin-dependent inhibition of lipolysis through GPR81. Cell Metab 11, 311-319 (2010).

11. Oh da, Y., et al. GPR120 is an omega-3 fatty acid receptor mediating potent anti-inflammatory and insulin-sensitizing effects. Cell 142, 687-698 (2010).

12. Hara, T., Hirasawa, A., Ichimura, A., Kimura, I. \& Tsujimoto, G. Free fatty acid receptors FFAR1 and GPR120 as novel therapeutic targets for metabolic disorders. J Pharm Sci 100, 3594-3601 (2011).

13. Kimura, I., et al. Short-chain fatty acids and ketones directly regulate sympathetic nervous system via G protein-coupled receptor 41 (GPR41). Proc Natl Acad Sci U S A 108, 8030-8035 (2011). 
14. Gotoh, C., et al. The regulation of adipogenesis through GPR120. Biochem Biophys Res Commun 354, 591-597 (2007).

15. Tanaka, T., et al. Free fatty acids induce cholecystokinin secretion through GPR120. Naunyn Schmiedebergs Arch Pharmacol 377, 523-527 (2008).

16. Miyauchi, S., et al. Distribution and regulation of protein expression of the free fatty acid receptor GPR120. Naunyn Schmiedebergs Arch Pharmacol 379, 427-434 (2009).

17. Kido, Y., et al. Tissue-specific insulin resistance in mice with mutations in the insulin receptor, IRS-1, and IRS-2. J Clin Invest 105, 199-205 (2000).

18. Bernal-Mizrachi, E., Wen, W., Stahlhut, S., Welling, C.M. \& Permutt, M.A. Islet beta cell expression of constitutively active Akt1/PKB alpha induces striking hypertrophy, hyperplasia, and hyperinsulinemia. J Clin Invest 108, 1631-1638 (2001).

19. Hosooka, T., et al. Dok1 mediates high-fat diet-induced adipocyte hypertrophy and obesity through modulation of PPAR-gamma phosphorylation. Nat Med 14, 188-193 (2008).

20. Ntambi, J.M., et al. Loss of stearoyl-CoA desaturase-1 function protects mice against adiposity. Proc Natl Acad Sci U S A 99, 11482-11486 (2002).

21. Gutierrez-Juarez, R., et al. Critical role of stearoyl-CoA desaturase-1 (SCD1) in the onset of diet-induced hepatic insulin resistance. J Clin Invest 116, 1686-1695 (2006).

22. Jeyakumar, S.M., et al. Fatty acid desaturation index correlates with body mass and adiposity indices of obesity in Wistar NIN obese mutant rat strains WNIN/Ob and WNIN/GR-Ob. Nutr Metab (Lond) 6, 27 (2009).

23. Brown, J.M., et al. Combined therapy of dietary fish oil and stearoyl-CoA desaturase 1 inhibition prevents the metabolic syndrome and atherosclerosis. Arterioscler Thromb Vasc Biol 30, 24-30 (2010).

24. Ichimura, A., Ruike, Y., Terasawa, K., Shimizu, K. \& Tsujimoto, G. MicroRNA-34a inhibits cell proliferation by repressing mitogen-activated protein kinase kinase 1 during megakaryocytic differentiation of K562 cells. Mol Pharmacol 77, 1016-1024 (2010).

25. Hara, T., et al. Novel selective ligands for free fatty acid receptors GPR120 and GPR40. Naunyn Schmiedebergs Arch Pharmacol 380, 247-255 (2009). 
26. Sun, Q., et al. Structure-activity relationships of GPR120 agonists based on a docking simulation. Mol Pharmacol 78, 804-810 (2010).

\section{REFERENCES (for METHODS)}

27. Gautier, L., Cope, L., Bolstad, B.M. \& Irizarry, R.A. affy--analysis of Affymetrix GeneChip data at the probe level. Bioinformatics 20, 307-315 (2004).

28. Poulain-Godefroy, O., Lecoeur, C., Pattou, F., Fruhbeck, G. \& Froguel, P. Inflammation is associated with a decrease of lipogenic factors in omental fat in women. Am J Physiol Regul Integr Comp Physiol 295, R1-7 (2008).

29. Meyre, D., et al. Genome-wide association study for early-onset and morbid adult obesity identifies three new risk loci in European populations. Nat Genet 41, 157-159 (2009).

30. Morandi, A., et al. The Q121 variant of ENPP1 may protect from childhood overweight/obesity in the Italian population. Obesity (Silver Spring) 17, 202-206 (2009).

31. Buzzetti, R., et al. PPAR-gamma2 Pro12Ala variant is associated with greater insulin sensitivity in childhood obesity. Pediatr Res 57, 138-140 (2005).

32. Jarvelin, M.R., et al. Ecological and individual predictors of birthweight in a northern Finland birth cohort 1986. Paediatr Perinat Epidemiol 11, 298-312 (1997).

33. Peeters, A., et al. Variants in the FTO gene are associated with common obesity in the Belgian population. Mol Genet Metab 93, 481-484 (2008).

34. Steffen, R., Potoczna, N., Bieri, N. \& Horber, F.F. Successful multi-intervention treatment of severe obesity: a 7-year prospective study with $96 \%$ follow-up. Obes Surg 19, 3-12 (2009).

35. Rouskas, K., et al. Association between BBS6/MKKS gene polymorphisms, obesity and metabolic syndrome in the Greek population. Int J Obes (Lond) 32, 1618-1625 (2008).

36. Balkau, B. [An epidemiologic survey from a network of French Health Examination Centres, (D.E.S.I.R.): epidemiologic data on the insulin resistance syndrome]. Rev Epidemiol Sante Publique 44, 373-375 (1996). 
37. Jaquet, D., Collin, D., Levy-Marchal, C. \& Czernichow, P. Adult height distribution in subjects born small for gestational age. Horm Res 62, 92-96 (2004).

38. Meyre, D., et al. R125W coding variant in TBC1D1 confers risk for familial obesity and contributes to linkage on chromosome 4p14 in the French population. Hum Mol Genet 17, 1798-1802 (2008).

39. Jarick, I., et al. Novel common copy number variation for early onset extreme obesity on chromosome 11q11 identified by a genome-wide analysis. Hum Mol Genet 20, 840-852 (2011).

40. Poskitt, E.M. Defining childhood obesity: the relative body mass index (BMI). European Childhood Obesity group. Acta Paediatr 84, 961-963 (1995).

41. Rolland-Cachera, M.F., et al. Body Mass Index variations: centiles from birth to 87 years. Eur J Clin Nutr 45, 13-21 (1991).

42. Siepel, A., et al. Evolutionarily conserved elements in vertebrate, insect, worm, and yeast genomes. Genome Res 15, 1034-1050 (2005).

43. Ramensky, V., Bork, P. \& Sunyaev, S. Human non-synonymous SNPs: server and survey. Nucleic Acids Res 30, 3894-3900 (2002).

44. Sunyaev, S., et al. Prediction of deleterious human alleles. Hum Mol Genet 10, 591-597 (2001).

45. Thomas, P.D., et al. PANTHER: a library of protein families and subfamilies indexed by function. Genome Res 13, 2129-2141 (2003).

46. Kumar, P., Henikoff, S. \& Ng, P.C. Predicting the effects of coding non-synonymous variants on protein function using the SIFT algorithm. Nat Protoc 4, 1073-1081 (2009).

47. Bromberg, Y., Yachdav, G. \& Rost, B. SNAP predicts effect of mutations on protein function. Bioinformatics 24, 2397-2398 (2008).

48. Ferrer-Costa, C., et al. PMUT: a web-based tool for the annotation of pathological mutations on proteins. Bioinformatics 21, 3176-3178 (2005). 


\section{ACKNOWLEDGEMENTS}

We are indebted to all subjects who participated in these studies. In Japan, the study was supported in part by research grants from the Japan Society for the Promotion of Science, the Ministry of Education, Culture, Sports, Science and Technology of Japan, the Japan Science and Technology Agency and the "Funding Program for World-Leading Innovative R\&D on Science and Technology (FIRST Program)," initiated by the Council for Science and Technology Policy. A.I. is a fellow supported by the Japan Society for the Promotion of Science. A.B. is a fellow supported by the EU funded EUROCHIP consortium. In France, the study was supported by 'le Conseil Régional Nord Pas de Calais / FEDER' and the 'Agence Nationale de la Recherche' (Programme de Recherche en Nutrition et Alimentation, SensoFAT). NFBC1986 received financial support from the Academy of Finland, University Hospital of Oulu (Finland), University of Oulu (Finland), the European Commission (EURO-BLCS, Framework 5 award QLG1-CT-2000-01643), and the Medical Research Council (G0500539, G0600705, PrevMetSyn/SALVE). We thank ABOS consortium and CIC-CCPPRB (Lille CHRU) team for their help in samples handling and clinical data collection. We are grateful to Marianne Deweirder and Frederic Allegaert for human DNA bank management.

\section{CONFLICT OF INTEREST STATEMENT}

The authors declare that they have no competing financial interests.

\section{AUTHOR CONTRIBUTIONS}

A.I. A.H. O.P-G. and A.B. are equally contributing first authors. G.T. and P.F. conceived the mouse and human project, respectively. A.I., A.H., A.B., P.F. and G.T. drafted the manuscript. O.P-G., H.C., D.M. and I.W. reviewed/edited the manuscript and contributed to discussion. A.H. and G.T. designed the mouse research. A.I., A.H., K.I. and G.T. created Gpr120 mutant mice. A.I., A.H., A.K., T.H., I.K., T-a.K., K.A., M.T., K.O, N.L. and G.T. conducted biochemical and histochemical analyses for the mouse study. A.I. and A.H. performed bioinformatic analysis for the mouse study. L.Y. and C.L. performed the statistical analyses, and A.B. contributed to statistical analyses for the human study. O.P-G. and I.W. designed the human expression gene study. A.L. performed the human expression gene study. H.C. and S.V. performed GPR120 
sequencing and variants genotyping, respectively. P.B., M.T., C.M., A.M., R.B., P.E., M-R.J., W.VH., L.VG., F.H., B.B., C.L-M., K.R., A.K. and F.P. contributed to cohort-study samples and researched data. 
Table 1. List of identified variants in GPR120 exons and association between p.R67C/rs6186610 or p.R270H non-synonymous variants and obesity.

\begin{tabular}{|c|c|c|c|c|c|c|c|c|c|c|c|}
\hline & & \multirow{2}{*}{ Variants } & \multirow{2}{*}{$\begin{array}{l}\text { Nucleotide } \\
\text { change }\end{array}$} & \multirow{2}{*}{$\begin{array}{l}\text { Chr10 } \\
\text { position }\end{array}$} & \multirow{2}{*}{$\mathrm{MAF}_{1}$} & \multirow{2}{*}{$\begin{array}{c}\mathrm{MAF}_{2} \\
\text { (controls/ } \\
N=7,654 \text { ) }\end{array}$} & \multirow{2}{*}{$\begin{array}{c}\mathrm{MAF}_{2} \\
\text { (casesI } \\
N=6,942)\end{array}$} & \multicolumn{2}{|c|}{$\begin{array}{c}\text { Adjustment: age and } \\
\text { gender }\end{array}$} & \multicolumn{2}{|c|}{$\begin{array}{c}\text { Adjustment: age, gender } \\
\text { and geography }\end{array}$} \\
\hline & & & & & & & & OR [95\%Cl] & $P$-value & OR $[95 \% \mathrm{Cl}]$ & P-value \\
\hline \multirow{2}{*}{ 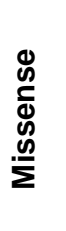 } & \multirow{2}{*}{$\underset{\frac{n}{2}}{\stackrel{\frac{\pi}{2}}{\frac{\pi}{5}}}$} & $\begin{array}{l}\text { p.R67C/ } \\
\text { rs6186610 }\end{array}$ & $C>T$ & $95,316,666$ & 0.05 & 0.043 & 0.055 & $\begin{array}{c}1.16 \\
{[1.02 ; 1.31]}\end{array}$ & 0.022 & $\begin{array}{c}1.13 \\
{[1.00 ; 1.28]}\end{array}$ & 0.060 \\
\hline & & p.R270H & $G>A$ & $95,337,031$ & 0.03 & 0.013 & 0.024 & $\begin{array}{c}1.62 \\
{[1.31 ; 2.00]}\end{array}$ & $8.00 \times 10^{-6}$ & $\begin{array}{c}1.58 \\
{[1.28 ; 1.95]}\end{array}$ & $2.17 \times 10^{-5}$ \\
\hline \multirow{4}{*}{ 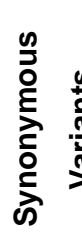 } & \multirow{4}{*}{ } & p.V38V & $G>A$ & $95,316,581$ & 0.0016 & - & - & - & - & - & - \\
\hline & & p.S192S & $G>A$ & $95,325,846$ & 0.0016 & - & - & - & - & - & - \\
\hline & & p.V243V & $C>T$ & $95,328,938$ & 0.0016 & - & - & - & - & - & - \\
\hline & & p.S264S & $G>A$ & $95,337,014$ & 0.0016 & - & - & - & - & - & - \\
\hline
\end{tabular}

Variant position was indicated according to the human genome build NCBI36/hg18. Association between p.R67C/rs6186610 or p.R270H variants and obesity was assessed by using a logistic regression adjusted for age/gender or for age/gender/geography, under an

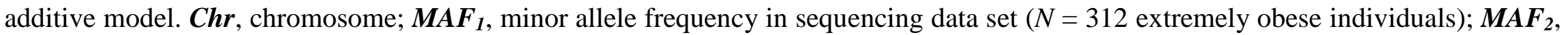
minor allele frequency in the large obesity case-control genotyping data set; $\boldsymbol{O R}$, odds ratio; $\boldsymbol{C I}$, confidence interval. 
Supplementary Table 1. Biochemical analyses of WT and GPR120-deficient mice fed a normal diet (ND) or a high-fat diet (HFD).

\begin{tabular}{|c|c|c|c|c|c|c|}
\hline \multirow{2}{*}{ Parameters } & \multicolumn{3}{|c|}{ ND } & \multicolumn{3}{|c|}{ HFD } \\
\hline & WT $(n=5)$ & GPR120 $^{-1-}(n=5)$ & $P$-value & WT $(n=15)$ & $\mathrm{GPR} 120^{-1-}(n=13)$ & P-value \\
\hline Total protein (g/dl) & $4.4 \pm 0.19$ & $4.86 \pm 0.08$ & 0.190 & $5.11 \pm 0.12$ & $4.95 \pm 0.08$ & 0.324 \\
\hline A/G ratio & $1.74 \pm 0.08$ & $1.74 \pm 0.06$ & 0.527 & $1.51 \pm 0.06$ & $1.57 \pm 0.06$ & 0.445 \\
\hline Albumin (mg/dl) & $2.8 \pm 0.15$ & $3.08 \pm 0.09$ & 0.062 & $3.05 \pm 0.1$ & $3.02 \pm 0.05$ & 0.755 \\
\hline Bilirubin (mg/dl) & $0.06 \pm 0.01$ & $0.05 \pm 0.01$ & 0.883 & $0.06 \pm 0$ & $0.04 \pm 0$ & 0.034 \\
\hline Triglyceride (mg/dl) & $27.6 \pm 7.16$ & $22.4 \pm 2.66$ & 0.593 & $62.4 \pm 9.04$ & $49.08 \pm 4.25$ & 0.216 \\
\hline Phospholipid (mg/dl) & $164.6 \pm 21.27$ & $164.6 \pm 5.52$ & 0.882 & $224.13 \pm 12.93$ & $258.62 \pm 10.32$ & 0.052 \\
\hline Nonesterified fatty acid $(\mu \mathrm{EQ} / \mathrm{l})$ & $556.8 \pm 108.63$ & $403 \pm 50.38$ & 0.202 & $886.27 \pm 76.52$ & $911.31 \pm 65.95$ & 0.809 \\
\hline HDL cholesterol (mg/dl) & $56 \pm 7.83$ & $55.6 \pm 2.2$ & 0.790 & $58.55 \pm 4.23$ & $71.5 \pm 3.24$ & 0.027 \\
\hline LDL cholesterol (mg/dl) & $4.2 \pm 0.65$ & $5.2 \pm 0.22$ & 0.076 & $11 \pm 2.27$ & $17.9 \pm 1.7$ & 0.027 \\
\hline Total cholesterol (mg/dl) & $85.8 \pm 11.58$ & $89 \pm 1.52$ & 0.553 & $130.87 \pm 9.87$ & $167.31 \pm 8.94$ & 0.012 \\
\hline Aspartate aminotransferase (AST) (IU/l) & $164.8 \pm 42.78$ & $85.8 \pm 14.14$ & 0.124 & $124.2 \pm 13.03$ & $145.85 \pm 20.19$ & 0.364 \\
\hline Alanine aminotransferase (ALT) (IU/I) & $23.2 \pm 7.24$ & $32.4 \pm 8.12$ & 0.402 & $53.8 \pm 12.52$ & $131 \pm 25.9$ & 0.009 \\
\hline
\end{tabular}

Data are means \pm standard error. $\boldsymbol{H D L}$, high density lipoprotein; $\mathbf{L D L}$, low density lipoprotein 
Supplementary Table 2. Clinical characteristics of the fourteen obese subjects and the fourteen selected lean subjects, matched for age and gender. No subjects carried the p.R270H variant and all of them were normoglycemic.

\begin{tabular}{lcc}
\hline Parameters & $\begin{array}{c}\text { Lean subjects } \\
(\boldsymbol{n}=\mathbf{1 4})\end{array}$ & $\begin{array}{c}\text { Obese subjects } \\
(\boldsymbol{n}=\mathbf{1 4})\end{array}$ \\
\hline \hline Age (years) & $41.57 \pm 10.54$ & $41.36 \pm 10.64$ \\
Sex ratio (men:women) & $4: 10$ & $4: 10$ \\
BMl $\left(\mathrm{kg} / \mathrm{m}^{2}\right)$ & $21.69 \pm 1.93$ & $52.71 \pm 8.68^{\star * *}$ \\
Total cholesterol (mg/dl) & $175.7 \pm 40.0$ & $194.8 \pm 34.5$ \\
HDL cholesterol (mg/dl) & $61.16 \pm 18.32$ & $48.56 \pm 11.24^{*}$ \\
LDL cholesterol (mg/dl) & $92.0 \pm 35.4$ & $123.1 \pm 28.3^{*}$ \\
Triglyceride $(\mathrm{mg} / \mathrm{dl})$ & $114.6 \pm 61.1$ & $115.6 \pm 49.5$ \\
\hline \hline
\end{tabular}

Data are means \pm standard deviation. BMI, body mass index; HDL, high density lipoprotein; $\mathbf{L D L}$, low density lipoprotein. Mann-Whitney analysis: $* * * P<0.001$; $* P<0.05$. 
Supplementary Table 3. Clinical characteristics of the populations sequenced for the four GPR120 exons.

\begin{tabular}{ccccccc}
\hline Screening & Subjects & $\boldsymbol{N}$ & $\begin{array}{c}\text { Sex ratio } \\
\text { (men:women) }\end{array}$ & Age (years) & BMI (kg/m²) & zBMI (kg/m²) \\
\hline \hline \multirow{2}{*}{$\begin{array}{c}\text { Morbid obese } \\
\text { patients }\end{array}$} & $\begin{array}{c}\text { French obese } \\
\text { adults }\end{array}$ & 121 & $26: 95$ & $48.16 \pm 12.40$ & $46.70 \pm 8.86$ & - \\
\cline { 2 - 7 } & $\begin{array}{c}\text { French obese } \\
\text { children }\end{array}$ & 191 & $92: 99$ & $11.48 \pm 3.17$ & - & $6.72 \pm 2.91$ \\
\hline \hline
\end{tabular}

Data are means \pm standard deviation. $\boldsymbol{B M I}$, body mass index. 
Supplementary Table 4. Clinical characteristics of the populations genotyped for both p.R67C/rs6186610 and p.R270H non-synonymous variants.

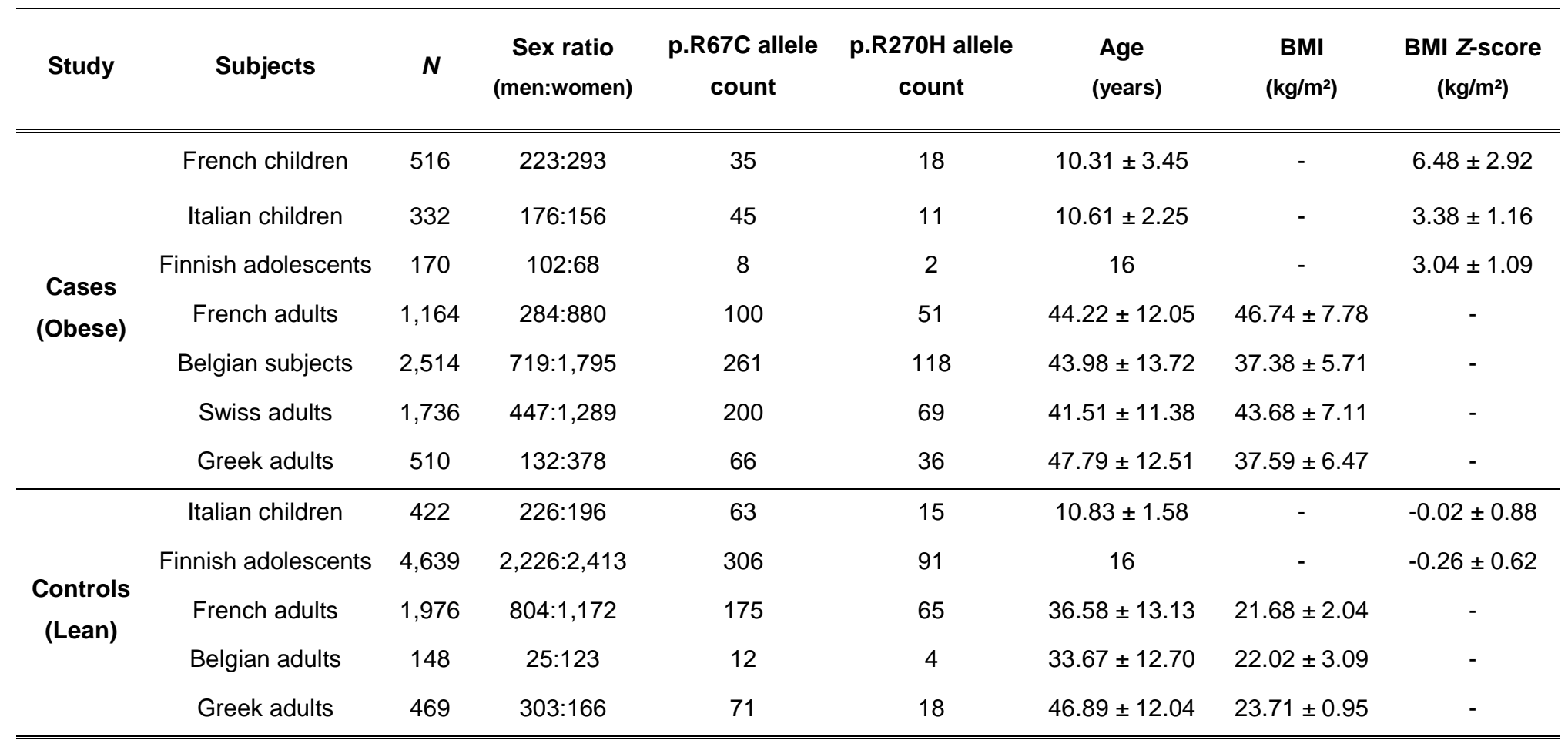

Data are means \pm standard deviation. BMI, body mass index. 
Supplementary Table 5. Transmission disequilibrium test analysis in 117 pedigrees who are polymorphic for the $\mathbf{p} . \mathbf{R} 270 \mathrm{H}$ variant.

\begin{tabular}{ccccc}
\hline Variant & T & Freq-T & RR & P-value \\
\hline p.R270R & 45 & 0.38 & 1 & \\
p.R270H & 73 & 0.62 & 1.62 & 0.009 \\
\hline \hline
\end{tabular}

T, alleles transmitted to obese offsprings; Freq-T, frequency of the allele transmitted to obese offsprings; $\boldsymbol{R} \boldsymbol{R}$, risk ratio. 
Supplementary Table 6. In Silico scores and predictions of functional consequences of both p.R67C/rs6186610 and p.R270H non-synonymous variants.

\begin{tabular}{llcc}
\hline Programs & & p.R67C / rs6186610 & p.R270H \\
\hline \hline \multirow{2}{*}{ PolyPhen } & PSIC Score difference & 2.26 & 1.58 \\
& Prediction & Probably damaging & Possibly damaging \\
\hline \multirow{2}{*}{ PANTHER } & SubPSEC & -6.47 & -5.91 \\
& Prediction & Probably damaging & Probably damaging \\
\hline \multirow{2}{*}{ SIFT } & Score & 0.00 & 0.08 \\
& Prediction & Probably damaging & Neutral \\
\hline \multirow{2}{*}{ SNAP } & Reliability Index & 5 & 0 \\
& Expected Accuracy (\%) & 87 & 58 \\
& Prediction & Probably damaging & Probably damaging \\
\hline \multirow{2}{*}{ PMUT } & Score & 0.13 & 0.30 \\
& Prediction & Neutral & Neutral \\
\hline \hline
\end{tabular}

PolyPhen computes the absolute value of the difference between profile scores of both allelic variants in the polymorphic position. A variant is predicted to be damaging if the PSIC score difference is $>1.7$. Regarding PANTHER, a subPSEC score less than -3 predicts deleterious effect. Regarding SIFT, amino acid substitutions with scores $<0.05$ are predicted to be deleterious. The reliability index (RI) for each SNAP prediction that ranges from 0 (low) to 9 (high) follows the formula: RI = INT(OUTnon-neutral OUTneutral)/10; results of SNAP predictions included only predictions with $\mathrm{RI} \geq 0$ and Expected Accuracy $\geq 50 \%$. Regarding PMUT, a pathogenicity index ranging from 0 to 1 (indexes $>0.5$ signal pathological mutations) has been calculated. 
Supplementary Table 7. Clinical characteristics of the 20 obese normoglycemic individuals carrying or not the p.R270H variant in a heterozygous state [10 carriers of the p.R270H variants versus 10 'wild-type' (WT) individuals]. All of them where matched for age, gender and BMI.

\begin{tabular}{lcc}
\hline Parameters & $\begin{array}{c}\text { p.R270H carriers } \\
(\boldsymbol{n}=\mathbf{1 0})\end{array}$ & $\begin{array}{c}\text { WT subjects } \\
(\boldsymbol{n}=\mathbf{1 0})\end{array}$ \\
\hline \hline Age (years) & $37.8 \pm 11.3$ & $38.0 \pm 10.9$ \\
Sex ratio (men:women) & $2: 8$ & $2: 8$ \\
BMI (kg/m²) & $48.2 \pm 4.6$ & $45.4 \pm 4.7$ \\
Total cholesterol (mg/dl) & $182.0 \pm 37.8$ & $189.1 \pm 28.3$ \\
HDL cholesterol (mg/dl) & $39.1 \pm 6.8$ & $47.9 \pm 9.5$ \\
LDL cholesterol (mg/dl) & $113.4 \pm 25.1$ & $121.3 \pm 24.7$ \\
Triglyceride $(\mathrm{mg} / \mathrm{dl})$ & $149.5 \pm 71.0$ & $96.2 \pm 27.3$ \\
\hline \hline
\end{tabular}

Data are means \pm standard deviation. BMI, body mass index; $\boldsymbol{H D L}$, high density lipoprotein; $\mathbf{L D L}$, low density lipoprotein. 


\section{FIGURE LEGENDS}

Figure 1. Obesity, hypertrophic adipocytes, accumulation of proinflammatory macrophages and hepatic steatosis in HFD-fed GPR120-deficient mice.

(a) Body weight changes of WT and GPR120-deficient mice fed ND, HFD (n=36-47).

(b) Indirect calorimetry in HFD-fed mice. Energy expenditure and respiratory quotient (RQ) (n=4-5). (c) Representative cross-sectional images of WT and GPR120-deficient mice subjected to micro-CT analysis of in situ accumulation of fat. Fat depots are demarcated (green) for illustration. (d) Hematoxylin and eosin stained epididymal WAT. Scale bar, $100 \mu \mathrm{m}$. Mean area of adipocytes $(\mathrm{n}=6)$. (e) Relative expression of $C d 11 b$, Cd68 and F4/80 mRNA in WAT (n=6). (f) Representative images of epididymal WAT stained with anti-F4/80 antibody. Scale bar, $100 \mu \mathrm{m}$. The number of F4/80 cells were

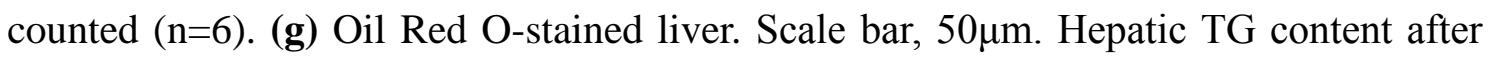
24hr fasting $(\mathrm{n}=13)$. Data represent means \pm s.e.m. ${ }^{*} P<0.05$ and $* * P<0.01$ versus the corresponding WT value. ND, normal diet; HFD, high-fat diet; WAT, white adipose tissue; $\boldsymbol{W T}$, wild-type; $\mathbf{T G}$, triglyceride.

Figure 2. Impaired glucose metabolism, adipogenesis and lipogenesis in HFD-fed GPR120-deficient mice.

(a) Fasting blood glucose and serum insulin levels ( $n=6-15)$. (b) Plasma glucose during ITT (left panel) and GTT (right panel) (n=12-14). (c) Phosphorylation of Akt (Ser 473) in WAT, liver and skeletal muscle after 24hr fasting (n=6-7). (d) Relative mRNA expression of Fabp4 and Scd1 in WAT or Scd1 in liver (n=6). (e) Protein expression of IRb, IRS1, IRS2, SCD1 and b-actin in WAT (f) Protein expression of IRS1, IRS2, SCD1 and b-actin in liver (g) Oil Red O-staining and TG content of MEF-derived 
adipocyte. Scale bar, 50mm. (h) Relative mRNA expression in MEF-derived adipocyte $(n=6)$. (i) The ratio of C18:1 to C18:0 in livers ( $n=6-8)$. (j) Non-esterified C16:1n7 palmitoleate in WAT and plasma $(n=4-7)$. (k) The ratio of Scd1 mRNA expression in liver and WAT ( $n=6-7)$. (l) The ratio of C16:1 to C16:0 in adipose tissues ( $n=6-8)$. (m) Hepatic Scd1 mRNA expression in mice infused with vehicle or TG:palmitoleate for $6 \mathrm{hr}$ ( $n=4-5)$. Data represent means \pm s.e.m. ${ }^{*} P<0.05$ and ${ }^{* *} P<0.01$ versus the corresponding WT value. $\boldsymbol{N D}$, normal diet; HFD, high-fat diet; WAT, white adipose tissue; WT, wild-type; ITT, insulin tolerance test; $\boldsymbol{G T T}$, glucose tolerance test; $\mathbf{T G}$, triglyceride; $\boldsymbol{M E F}$, mouse embryonic fibroblast.

Figure 3. GPR120 expression in human obese tissue samples, and effect of GPR120 variants on $\left[\mathrm{Ca}^{2+}\right]_{i}$ response and GLP-1 secretion.

(a) GPR120 mRNA level in human SC and OM adipose tissues of lean (white bars; $\mathrm{n}=14$ ) and obese (black bars; $n=14$ ) normoglycemic individuals. Mann-Whitney analysis: $* * * P=0.0004$ and $* * P=0.003$. (b) ALA-induced $\left[\mathrm{Ca}^{2+}\right]_{\mathrm{i}}$ responses in cells expressing WT GPR120 or p.R67C or p.R270H variant. (c) ALA-induced GLP-1 secretion in NCI-H716 cells expressing either GPR120 WT, p.R67C or p.R270H receptor. (d) Effect of transfection with GPR120 variants on ALA-induced $\left[\mathrm{Ca}^{2+}\right]_{\mathrm{i}}$ response in cells stably expressing WT GPR120. (e) Effect of co-expression of human GPR120 p.R270H variant with WT GPR120 on ALA-induced $\left[\mathrm{Ca}^{2+}\right]_{\mathrm{i}}$ response. Schematic diagram of constructs (upper panel). Expression of WT and p.R270H (lower left panel). Concentration- $\left[\mathrm{Ca}^{2+}\right]_{\mathrm{i}}$ response for ALA in cells expressing WT/WT, $\mathrm{WT} / \mathrm{R} 270 \mathrm{H}$ or $\mathrm{R} 270 \mathrm{H} / \mathrm{WT}$ receptors (lower right panel). ${ }^{* *} P<0.01$ versus the corresponding control value. SC, subcutaneous; $\boldsymbol{O M}$, omental (visceral); $\mathbf{L N}$, lean; $\boldsymbol{O B}$, 
obese; WT, wild-type; $\boldsymbol{R F U}$, relative fluorescence unit; $\boldsymbol{R F I}$, relative fluorescence intensity; $N S$, not significant. 
Figure 1

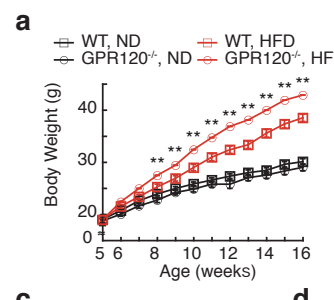

b

c

d epididymal WAT,
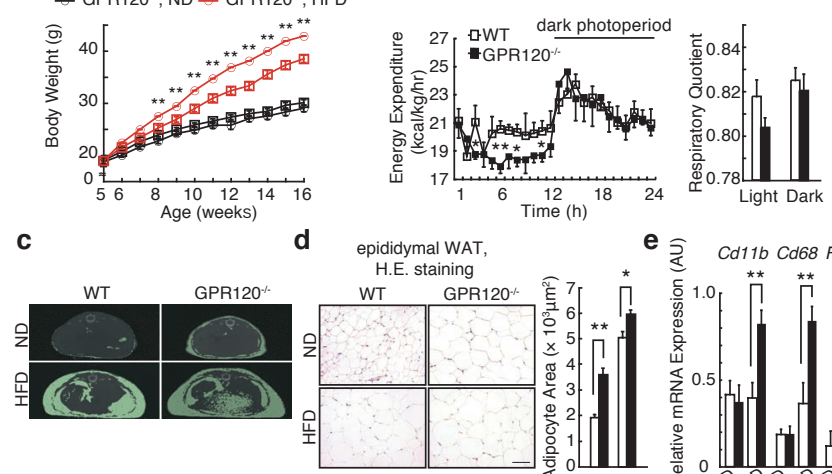

ร) Cd11b Cd68 F4/80
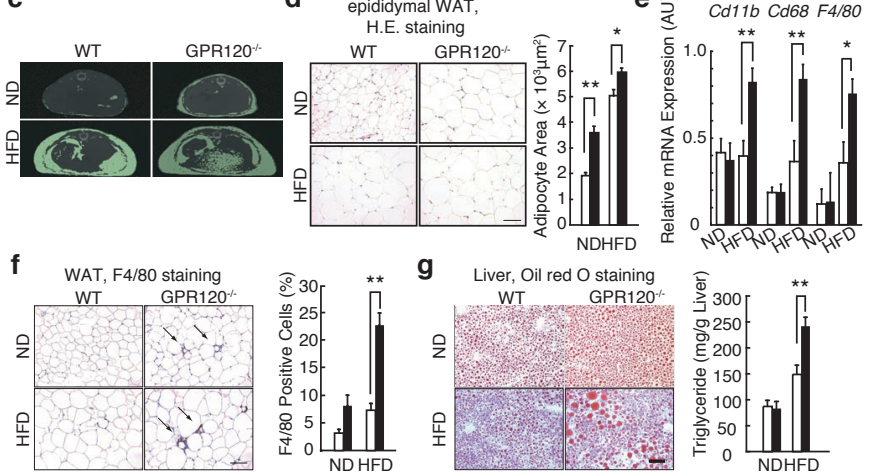
a

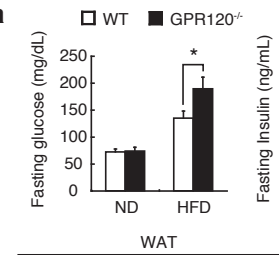

d

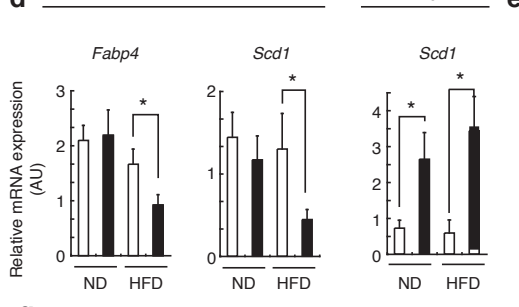

b

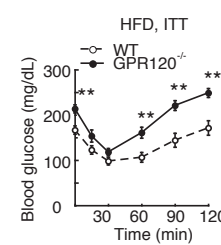

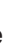
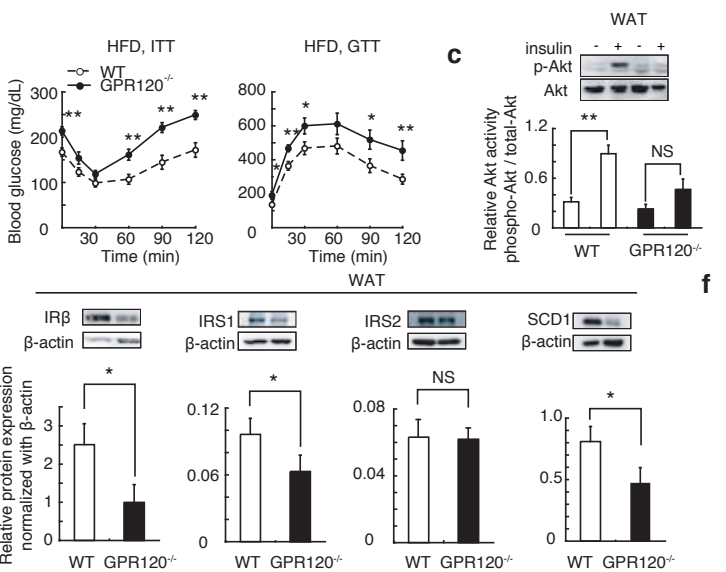

WT GPR120

n

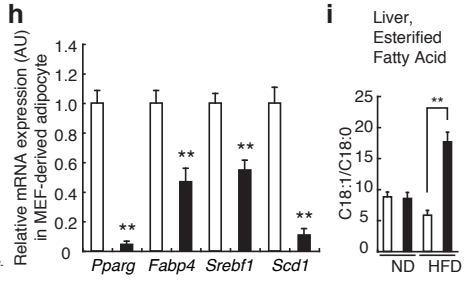

$\frac{\text { WT GPR120 }}{\sum_{\text {WT GPR120 }}^{*}}$

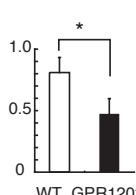

WT GPR120

$\begin{array}{ll}\text { WAT, } & \text { Plasma, } \\ \text { Nonesterified } & \text { Nonesterifie }\end{array}$ $\begin{array}{ll}\text { Nonesterified } & \text { Nonesterified } \\ \text { Fatty Acid } & \text { Fatty Acid }\end{array}$

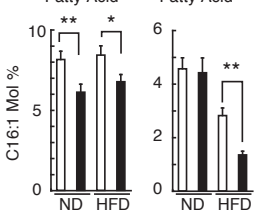

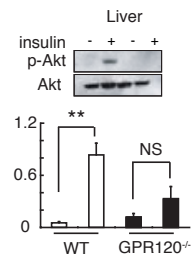
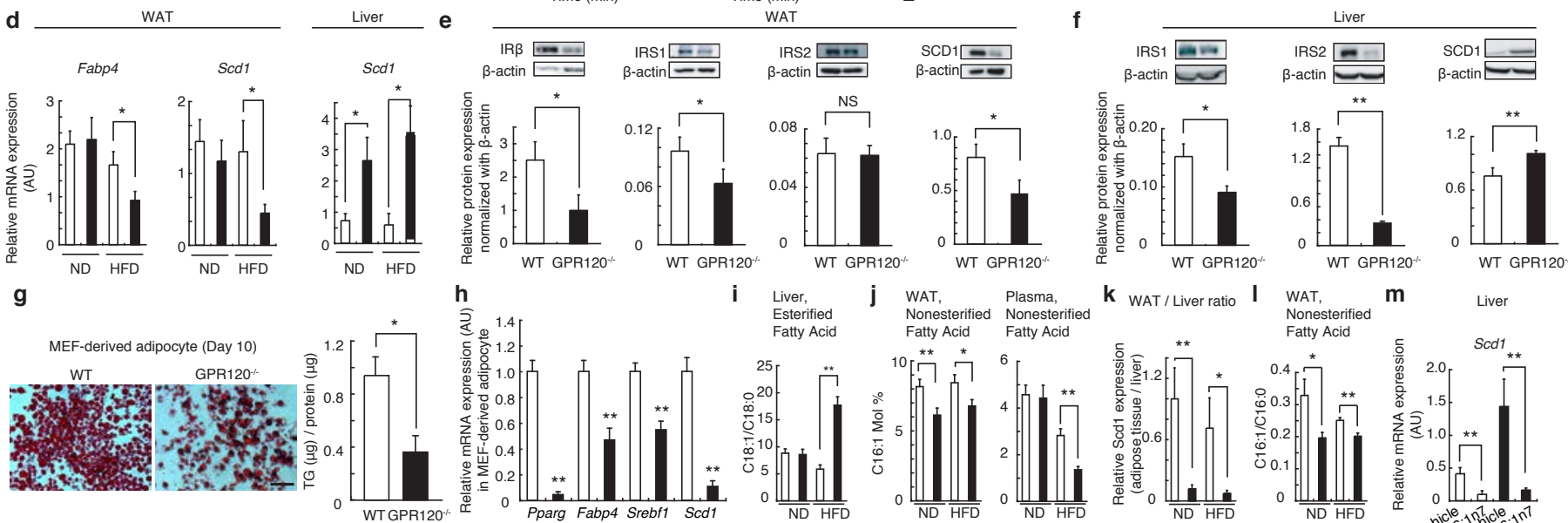

WAT,

Nonesterified
Fatty Acid

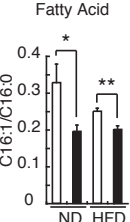

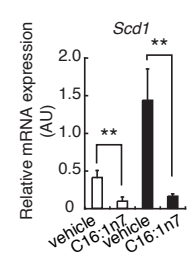


京都大学

KYOTO UNIVERSITY

a

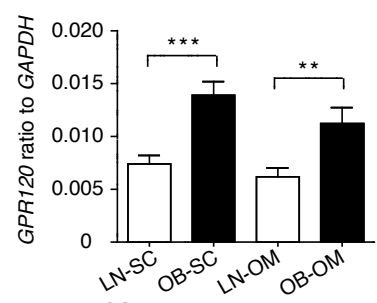

C

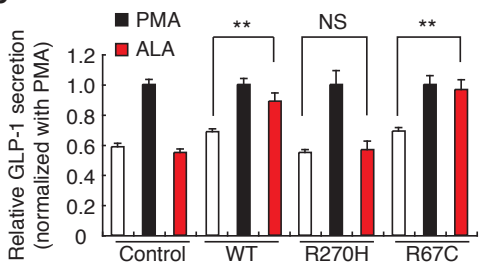

e

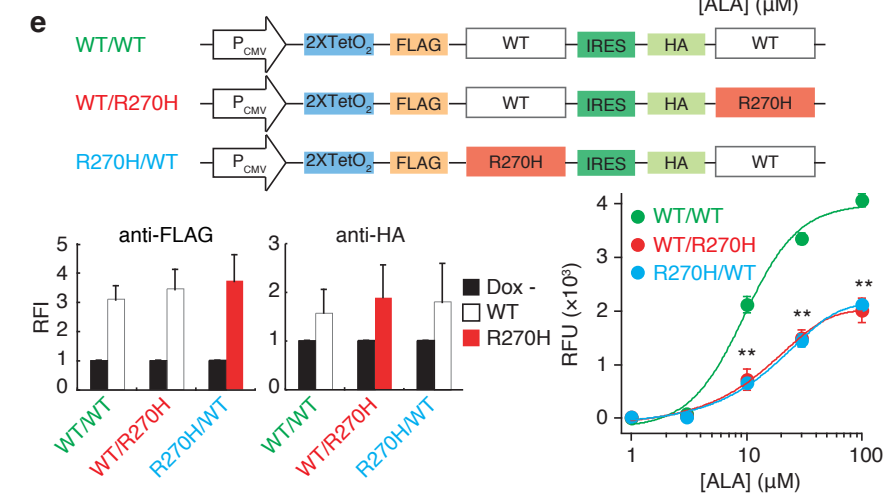

WT/R27OH $-P_{\text {CuV }}-2 \times T_{e+O}-$ FLAG $-W T$ IRES - HA - R270H

R270H/WT

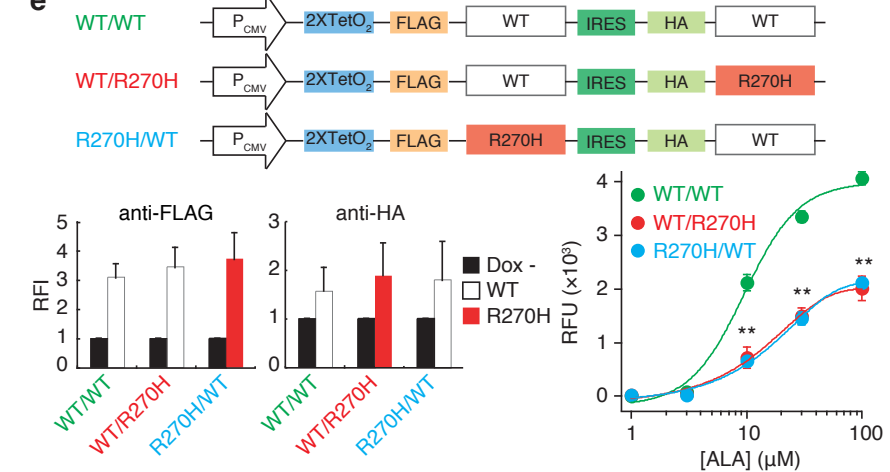

b
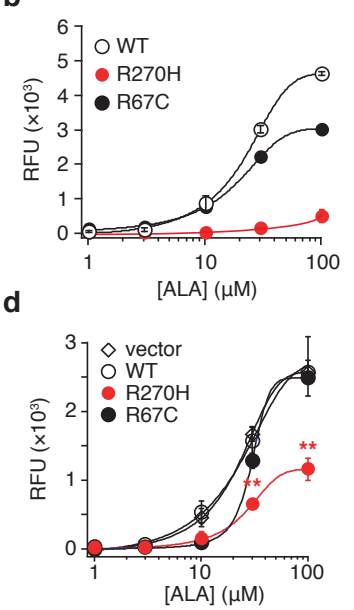
a

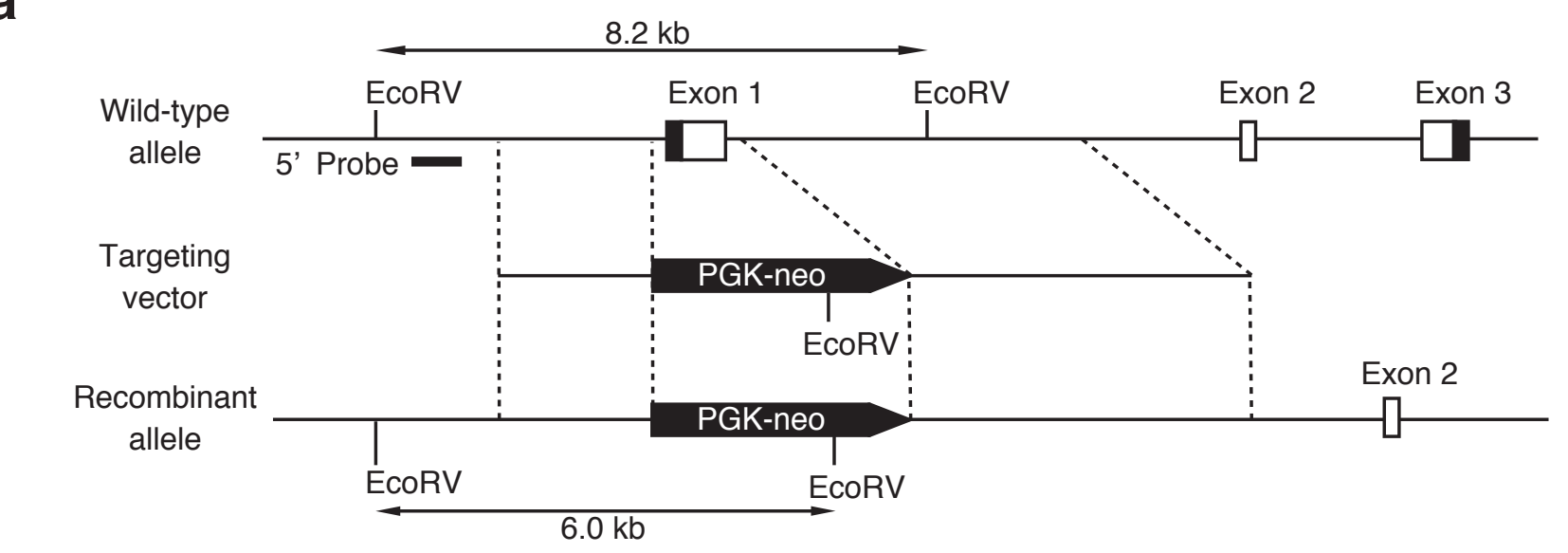

b

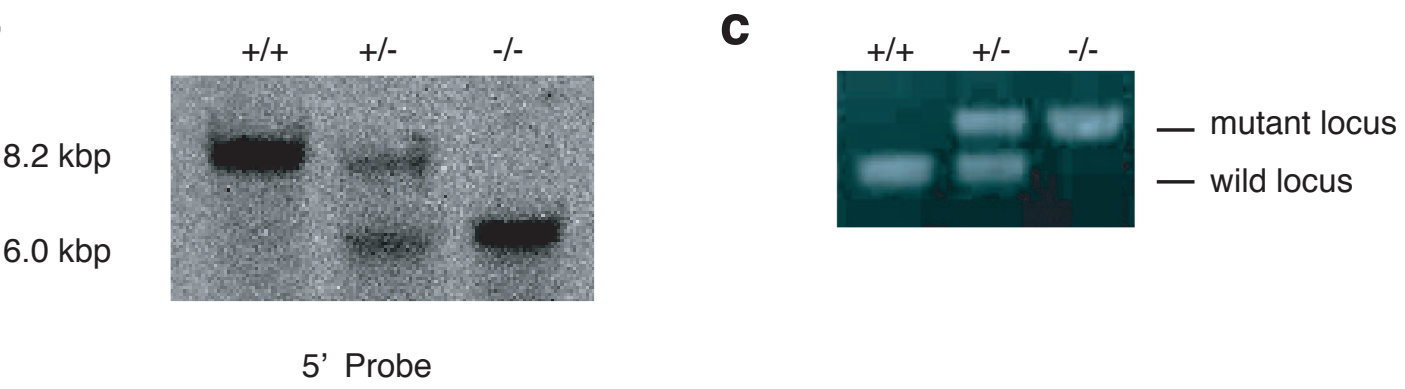

d

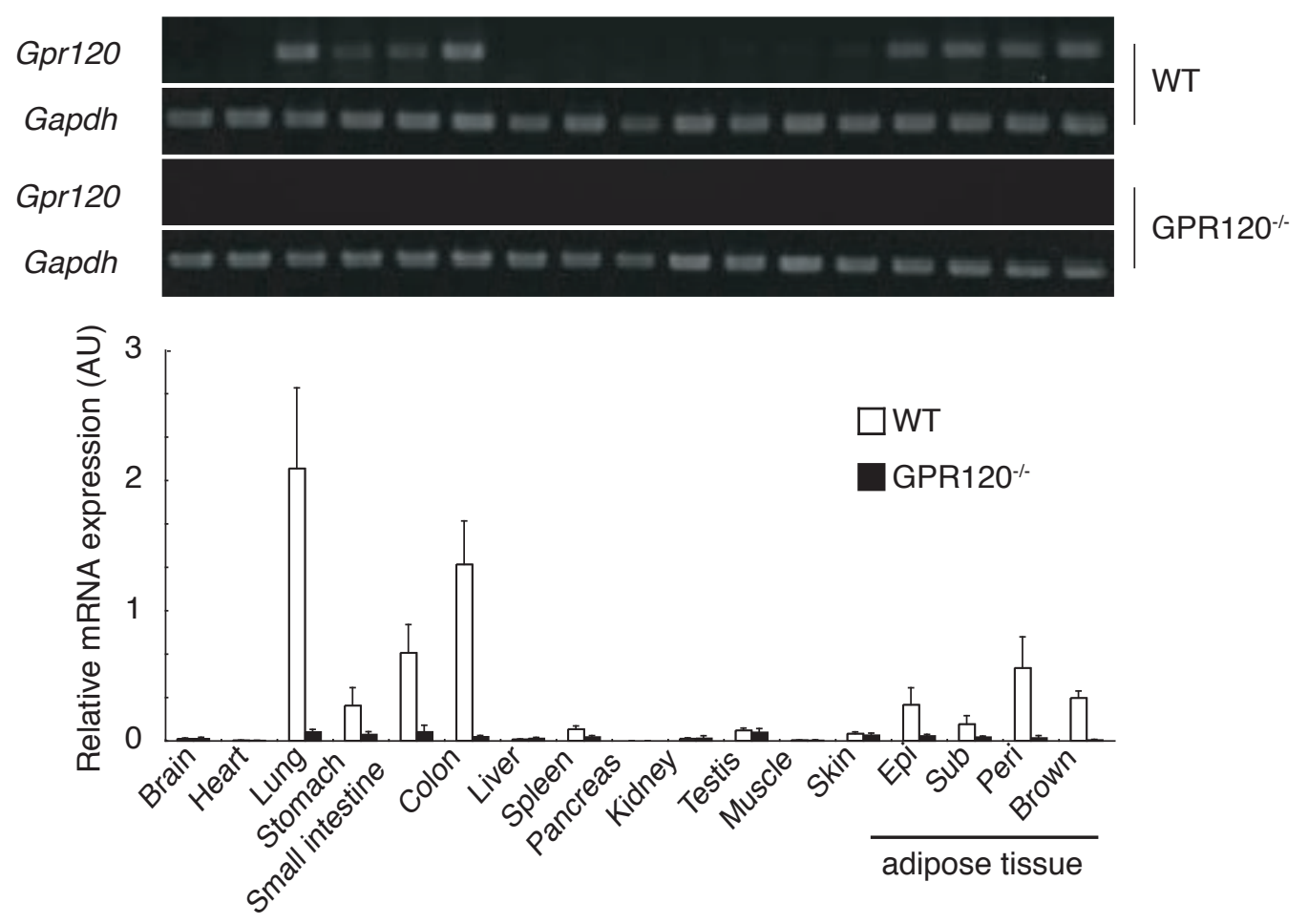

\section{Supplementary Figure 1. Targeted disruption and tissue distribution of Gpr120 in mice.}

(a) A targeting vector was constructed by the ligation of three fragments: the 5' and 3' homology recombination arms and a fragment of the LacZ-PGK-neo cassette. A 1.2-kbp fragment of mouse DNA containing the exon coding for Gpr120 was replaced with the LacZ-PGK-neo cassette. The linearized targeting vector was electroporated into 129/Sv ES cells. (b) A 5' probe used for Southern blotting is shown below the map of the target allele. The 8.5-kbp and 6.0-kbp fragments, which correspond to the WT and mutant alleles, respectively, were detected by Southern blotting from genomic DNA digested with EcoRV enzyme. (c) Genotypes of mice were determined by PCR using three primers as described in the Methods section. (d) The tissue distribution of Gpr120 mRNA expression in mouse was measured by RT-PCR (upper panel) and real-time quantitative RT-PCR (lower panel) (n=6). $\boldsymbol{S u b}$, subcutaneous adipose tissue; $\boldsymbol{E p} \boldsymbol{i}$, epididymal adipose tissue; $\boldsymbol{P e r i}$, peri-renal adipose tissue; $\boldsymbol{W T}$, wild-type. 
a
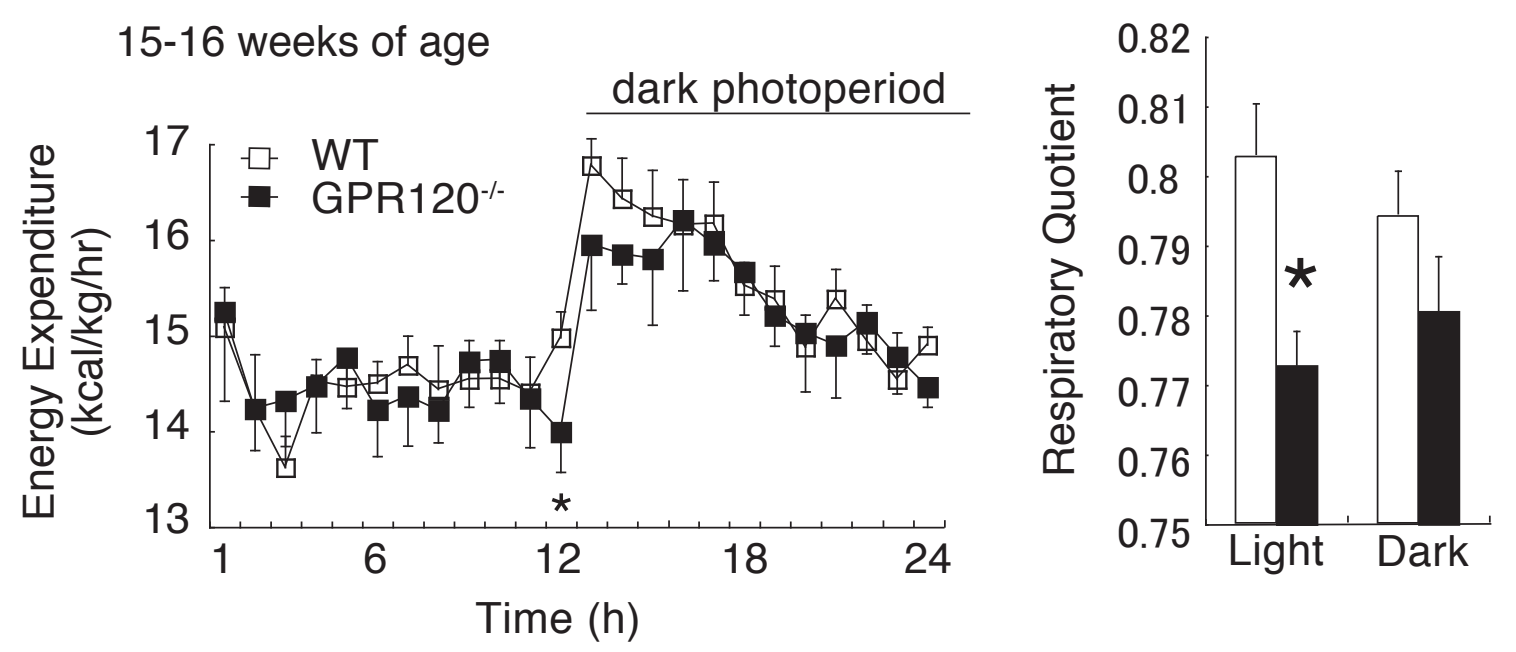

b

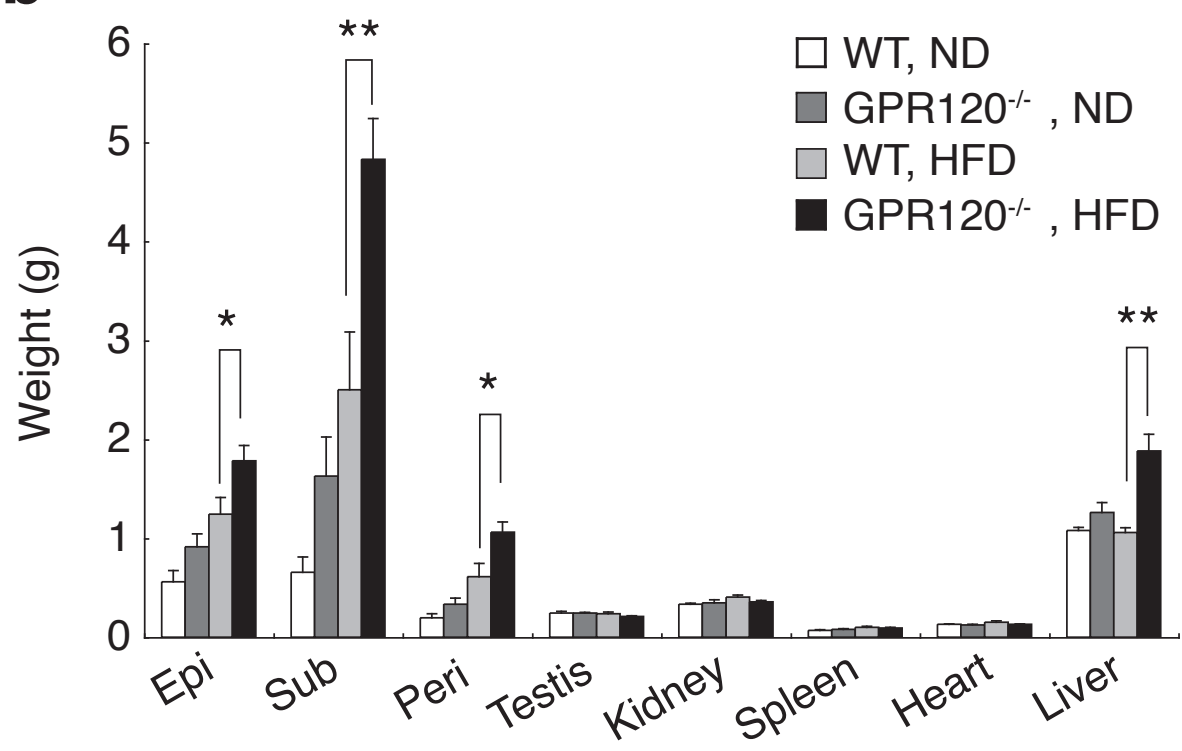

C

subcutaneous WAT, H.E. staining

$\square$ WT

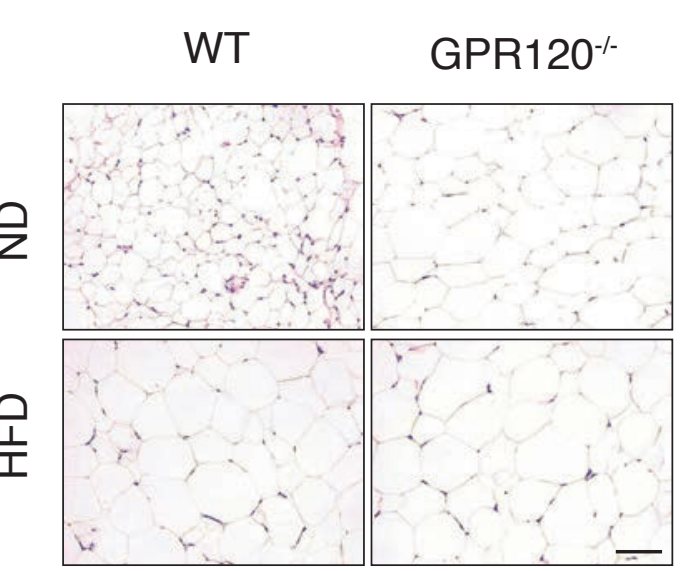

- GPR120 $\%$

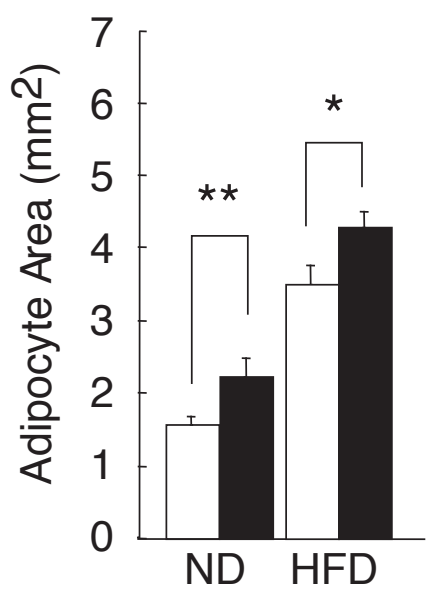

Supplementary Figure 2. Obesity and hypertrophic adipocytes in HFD-fed GPR120-deficient mice. (a) Energy expenditure (left panel) and respiratory quotient (right panel) in HFD-fed WT and GPR120deficient mice (15-16 weeks of age, $n=4-6$ ) (b) Weights of various tissues from 16-week-old GPR120deficient mice or WT mice fed ND $(n=5)$ or HFD $(n=7)$. (c) Hematoxylin and eosin stained subcutaneous adipose tissue from 16-week-old WT and GPR120-deficient mice fed ND or HFD. Scale bar, $100 \mu \mathrm{m}$. Mean area of adipocytes of 16-week-old WT and GPR120-deficient mice fed ND or HFD (n=6). Data represent means \pm standard error. $* P<0.05$ and $* * P<0.01$ versus the corresponding WT value. $\boldsymbol{S u b}$, subcutaneous adipose tissue; $\boldsymbol{E} \boldsymbol{p i}$, epididymal adipose tissue; Peri, peri-renal adipose tissue; $\boldsymbol{N D}$, normal diet; $\boldsymbol{H F D}$, high-fat diet; $\boldsymbol{W} \boldsymbol{T}$, wild-type. 
a
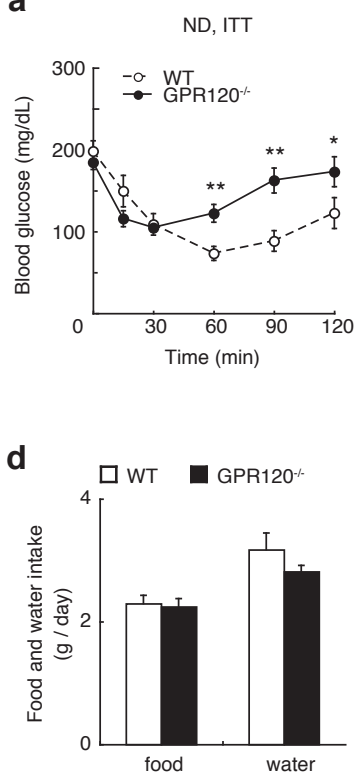

h
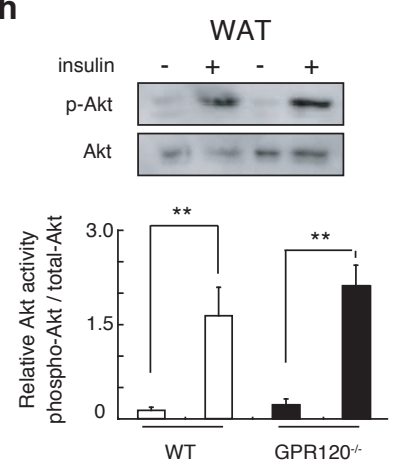

ND, GTT

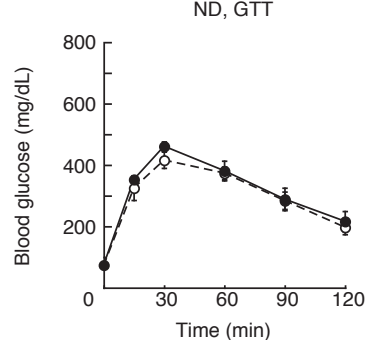

b

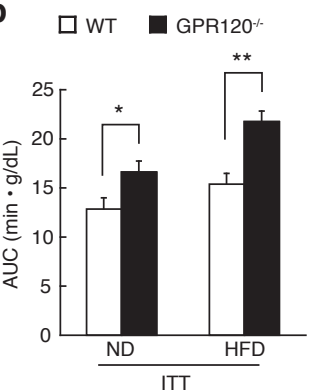

C

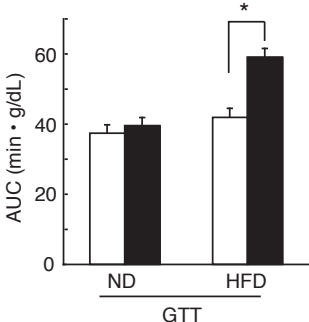

$\square$ WT $\quad$ GPR120
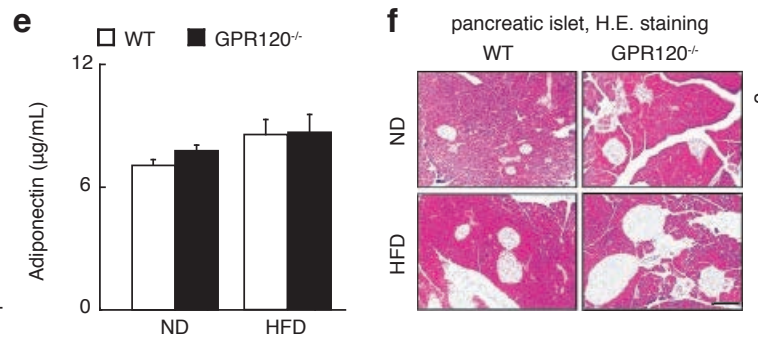

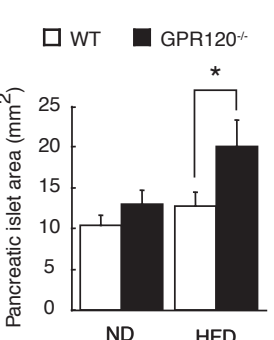

g pancreatic islet, Ki67 staining
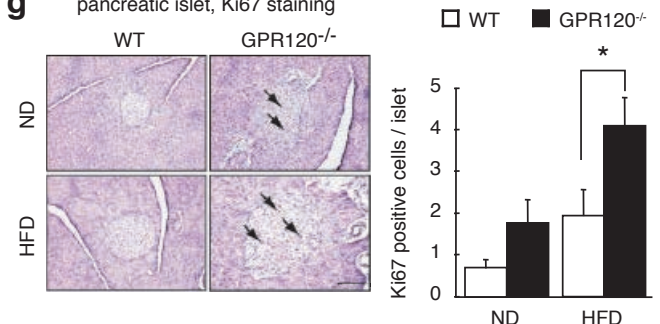

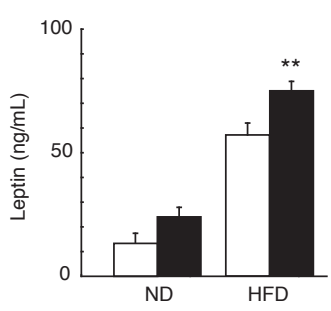

i
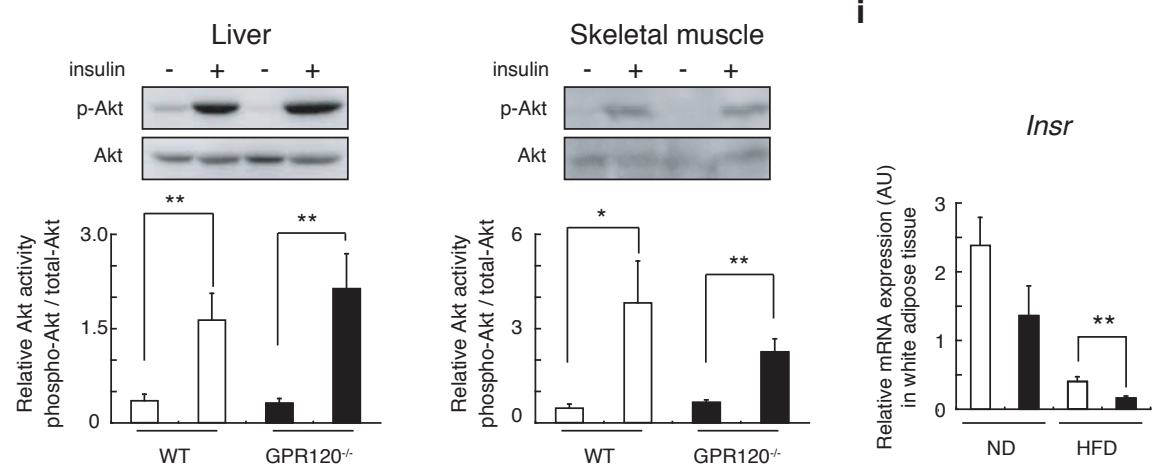

Irs1

Irs2
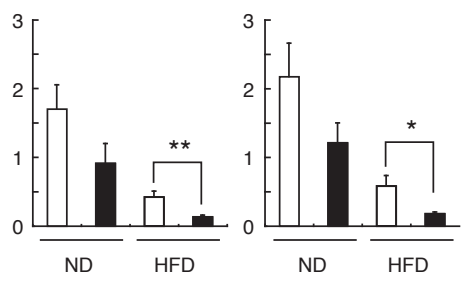

\section{Supplementary Figure 3. Impaired glucose metabolism in GPR120-deficient mice on ND.}

(a) ITT and GTT in 16-week-old WT and GPR120-deficient mice fed ND ( $\mathrm{n}=12-14)$. (b) AUC of the ITT and GTT ( $\mathrm{n}=12-$ 14). (c) Plasma leptin abundance in 16-week-old WT and GPR120-deficient mice fed ad libitum with ND or HFD ( $\mathrm{n}=10$ ). (d) Food and water intake of 16-week-old WT and GPR120-deficient mice fed ad libitum HFD (n=10). (e) Plasma adiponectin abundance in 16-week-old WT and GPR120-deficient mice fed ad libitum with ND or HFD (n=10). (f) Hematoxylin and eosin stained pancreatic islet from 16-week-old WT and GPR120-deficient mice fed ND or HFD. Scale bar, 50 $\mu$ m. Mean area of pancreatic islet from 16-week-old WT and GPR120-deficient mice fed ND or HFD. The area occupied by pancreatic islets was quantified as described in the Methods section. Results are shown as the mean and corresponding standard error. for six animals per group. ${ }^{*} \mathrm{P}<0.05$ versus the corresponding WT value. (g) Representative images of pancreatic islets from 16-week-old WT and GPR120-deficient mice fed ND or HFD stained with anti-Ki67 antibody. Scale bar, 50 $\mu \mathrm{m}$. The number of Ki67 cells was counted as described in the Methods section. (h) Phosphorylation of Akt (Ser473) in WAT, liver and skeletal muscle of 20-week-old WT and GPR120-deficient mice fed ND after $24 \mathrm{hr}$ fasting. The bottom panels show the quantitative analysis of p-Akt protein normalized to Akt levels in the respective samples (n=6-7). (i) Relative expression of Insr, Irs 1 , and Irs 2 mRNA in adipose tissue from 20-week-old WT and GPR120-deficient mice fed ND or HFD measured using qRT-PCR (n=6). Gapdh mRNA expression was used as an internal control. Results are shown as the mean and corresponding standard error for six to seven animals per group. $* P<0.05$ and $* * P<0.01$ vers us the corresponding WT value. $\boldsymbol{N D}$, normal diet; $\boldsymbol{H F D}$, high-fat diet; $\boldsymbol{W A T}$, white adipose tissue; $\boldsymbol{W T}$, wild-type; $\boldsymbol{I T T}$, insulin tolerance test; $\boldsymbol{G T T}$, glucose tolerance test; $\boldsymbol{A} \boldsymbol{U C}$, area under the curve. 
a
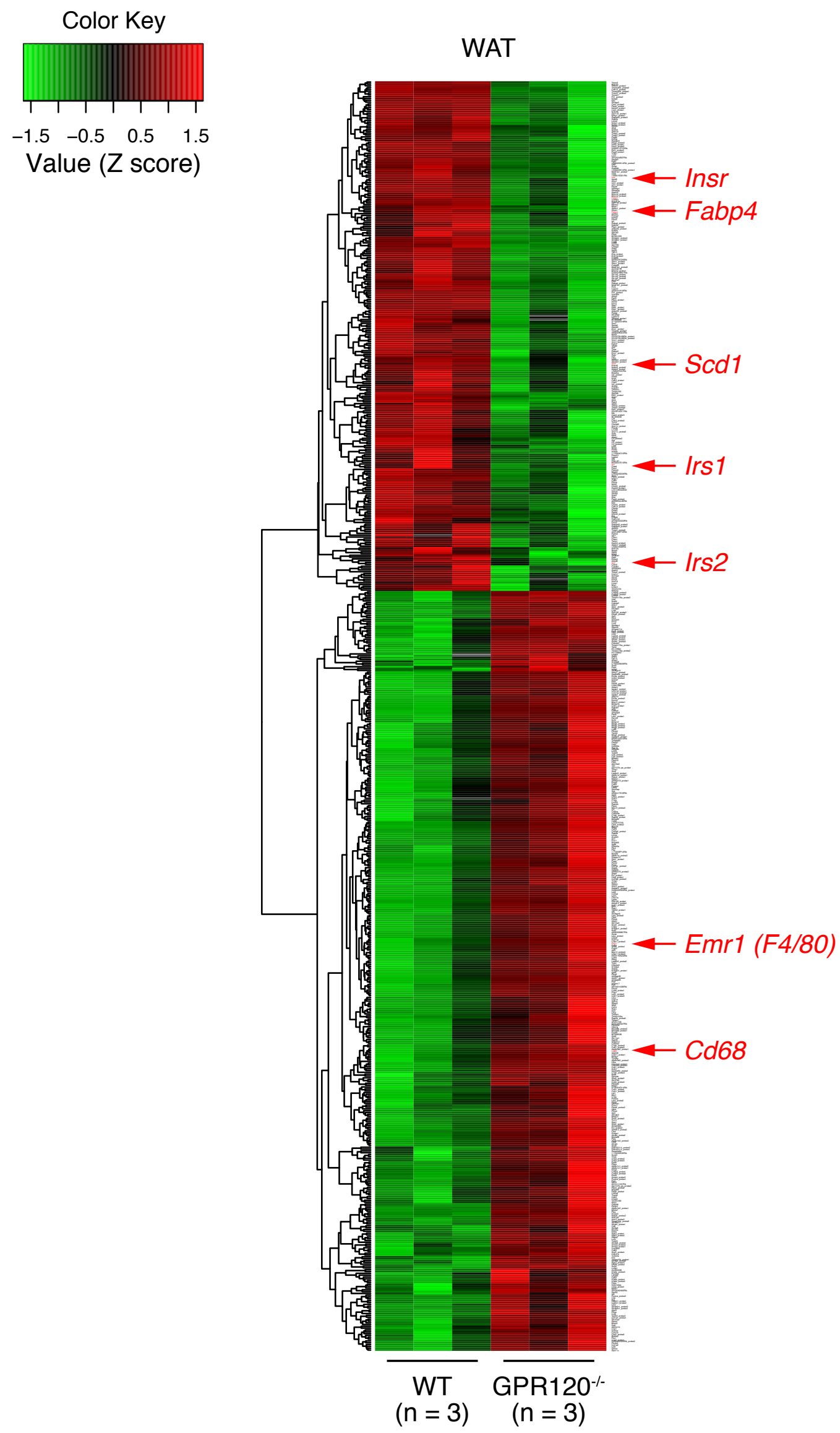

Supplementary Figure 4. Changes in gene expression and connectivity map of differentially expressed genes in WAT of HFD-fed GPR120-deficient mice.

(a) Heatmap comparison of epididymal white adipose tissue of HFD-fed WT and GPR120-deficient mice using gene expression microarray analysis. Gene changes were considered significant if $P<0.05$ and fold-change $>1.5$. The heat map was generated using z-scores across all samples. $\boldsymbol{H F D}$, high-fat diet; $\boldsymbol{W T}$, wild-type; $\boldsymbol{W A T}$, white adipose tissue. 


\section{Supplementary Figure 4}

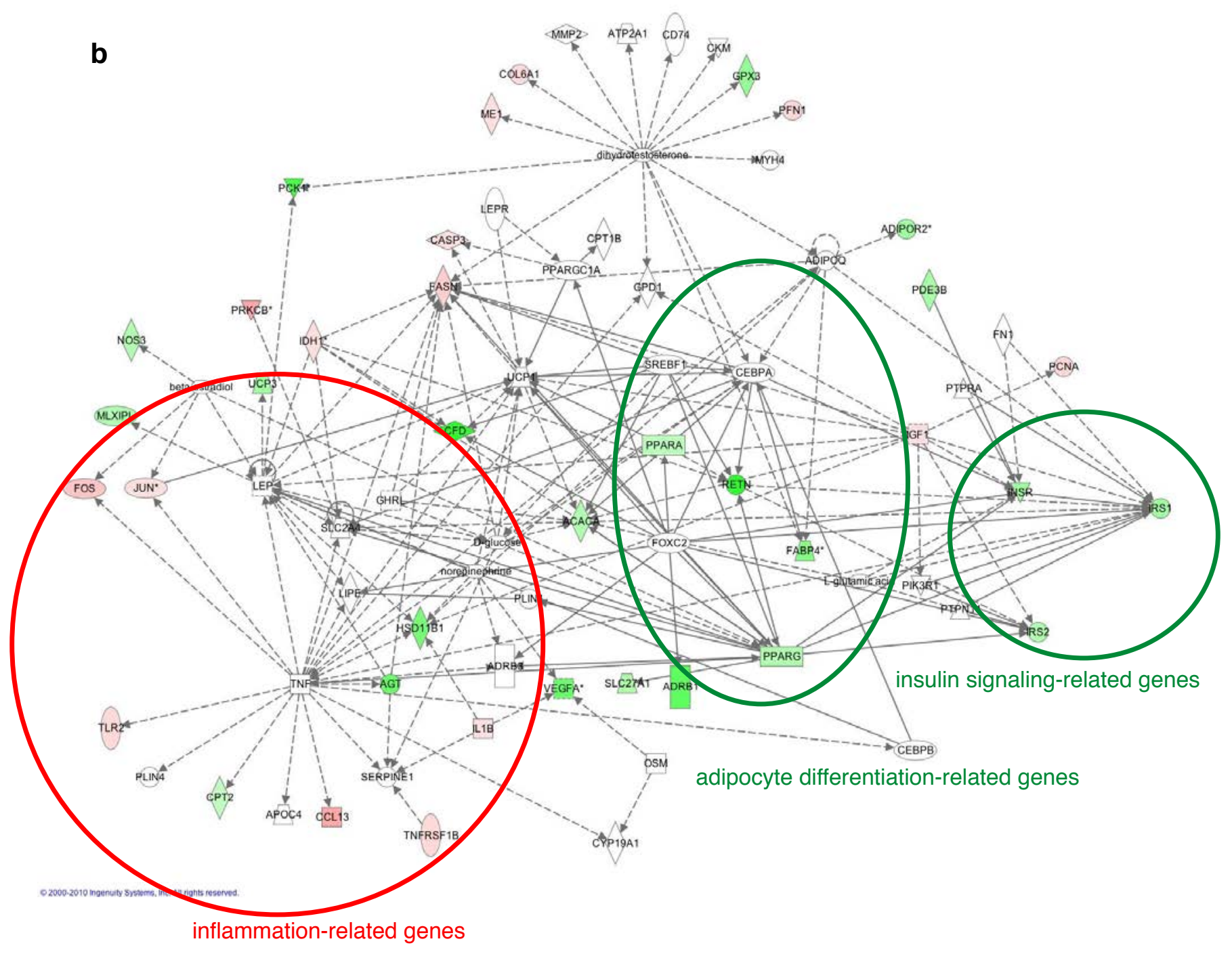

Supplementary Figure 4. Changes in gene expression and connectivity map of differentially expressed genes in WAT of HFD-fed GPR120-deficient mice.

(b) The network was analyzed using IPA software and is displayed graphically. Shaded genes were determined to be significant following statistical analysis. Significance was determined by a Student's t-test on predefined sample groups $(\mathrm{n}=3)$. The intensity of the shading shows to what degree each gene was up or down-regulated in epididymal adipose tissue of HFD-fed GPR120-deficient mice compared to WT mice. The genes shaded red were up-regulated and those that are green were down-regulated. A solid line represents a direct interaction between the two gene products and a dotted line indicates that there was an indirect interaction. $\boldsymbol{H F D}$, high-fat diet; $\boldsymbol{W A T}$, white adipose tissue; $\boldsymbol{W T}$, wild-type. 


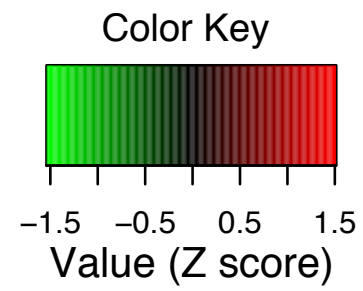

Liver

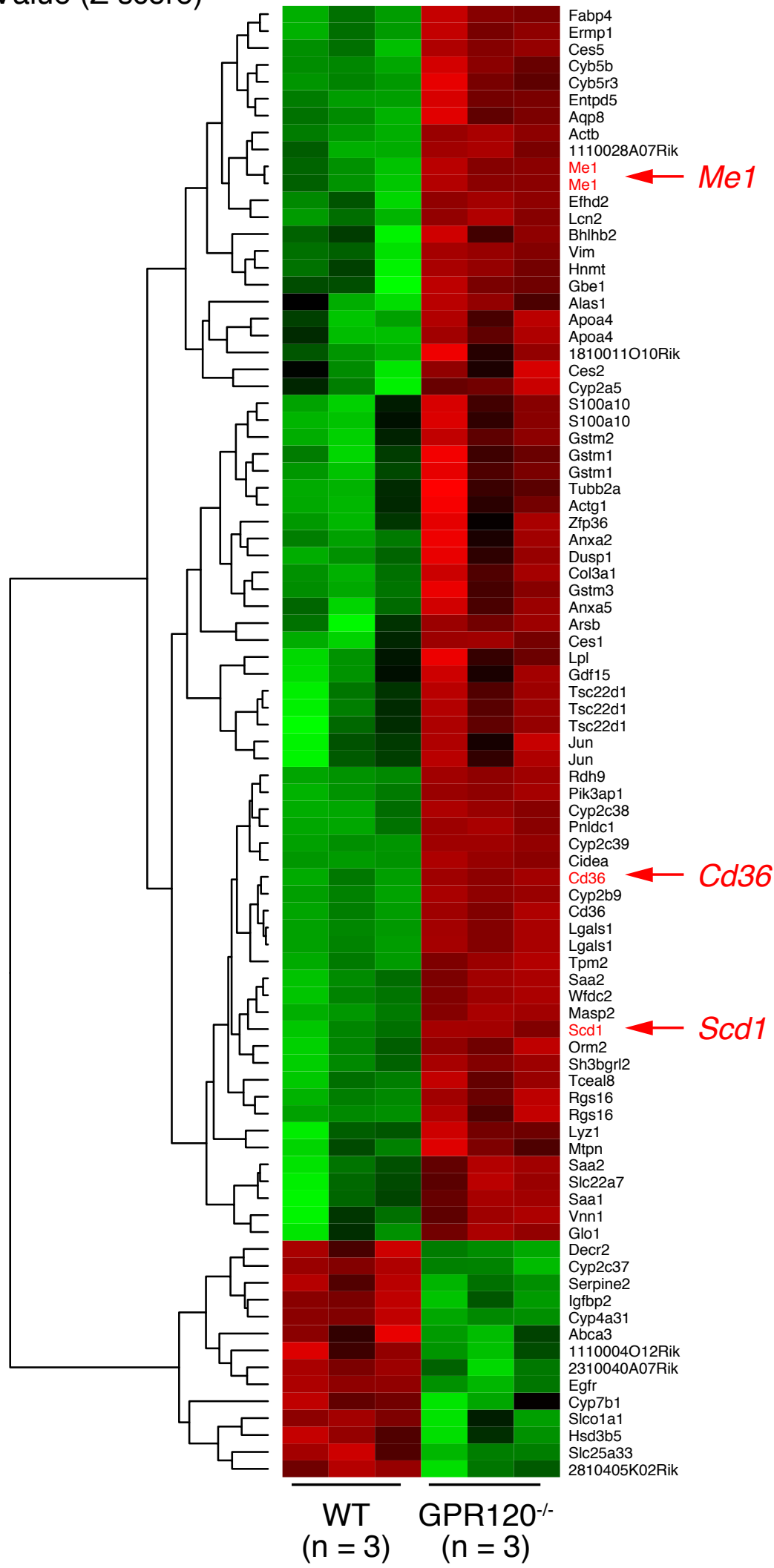

Supplementary Figure 5. Changes in gene expression in Liver of HFD-fed GPR120-deficient mice.

Heatmap comparison of livers from 16-week-old HFD-fed WT and GPR120-deficient mice using gene expression microarray analysis. Significance was determined by a Student's t-test on predefined sample groups $(n=3)$. Gene changes were considered significant if $P<0.05$ and fold-change $>1.5$. The heat map was generated using $\mathrm{z}$-scores across all samples. $\boldsymbol{H F D}$, high-fat diet; $\boldsymbol{W T}$, wild-type. 


\section{Supplementary Figure 6}

a HFD, Adipose, Esterified Fatty Acids

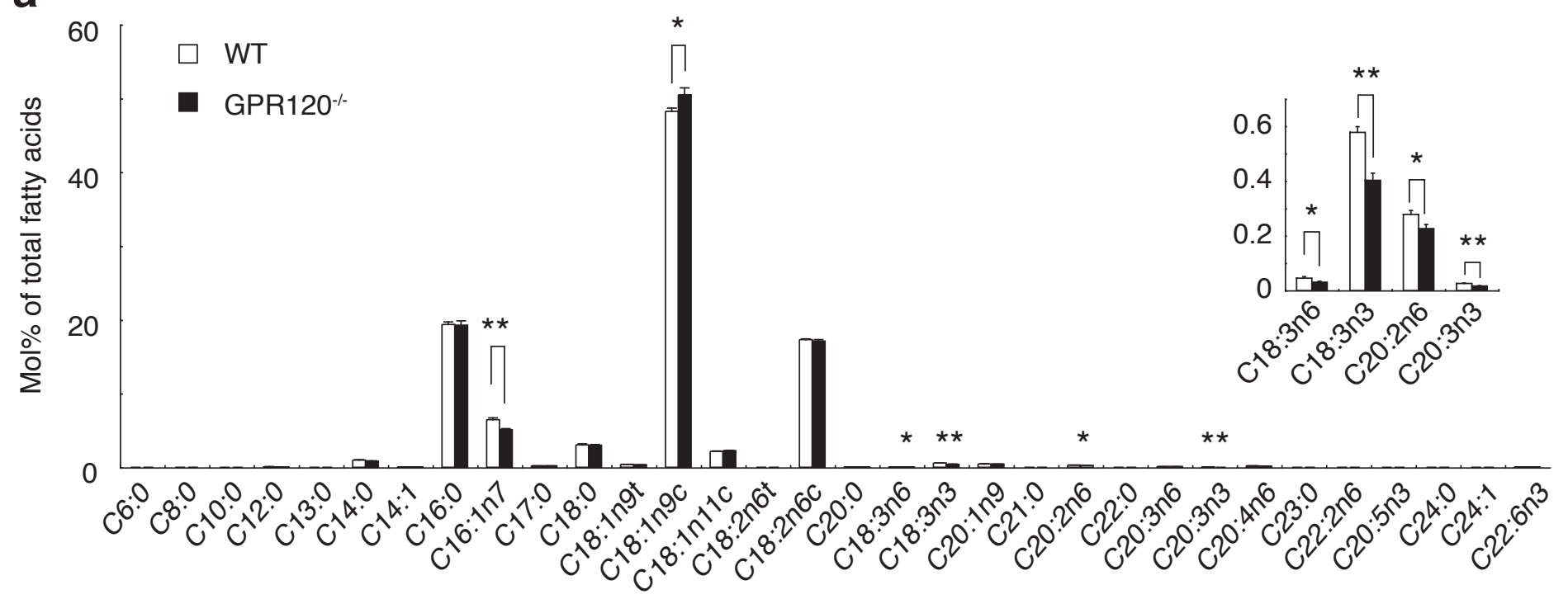

HFD, Liver, Esterified Fatty Acids

b

C

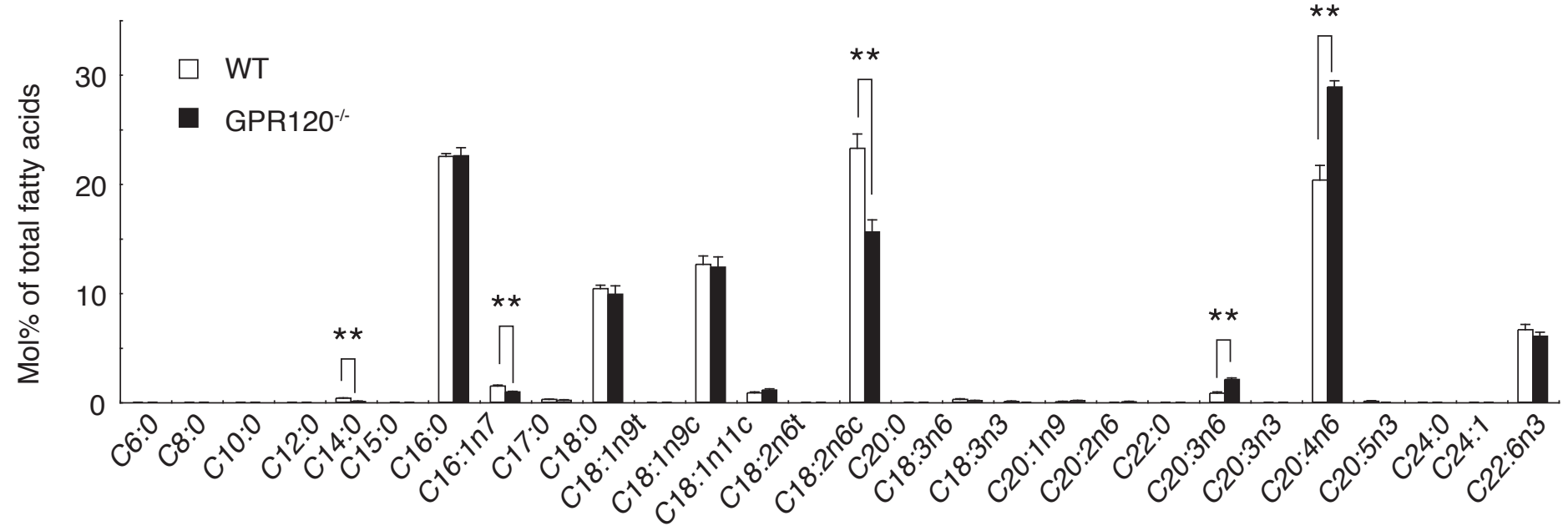


d

ND, Adipose tissue, Esterified Fatty Acids

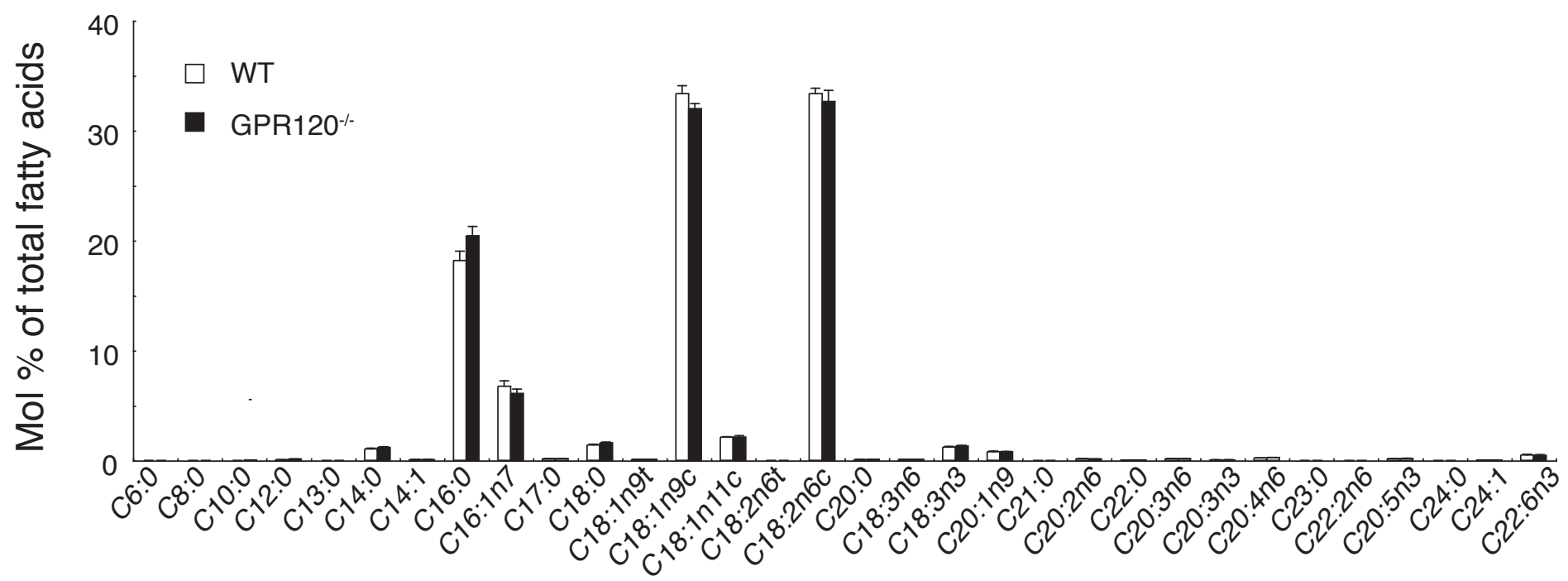

e

ND, Liver Esterified, Fatty Acids

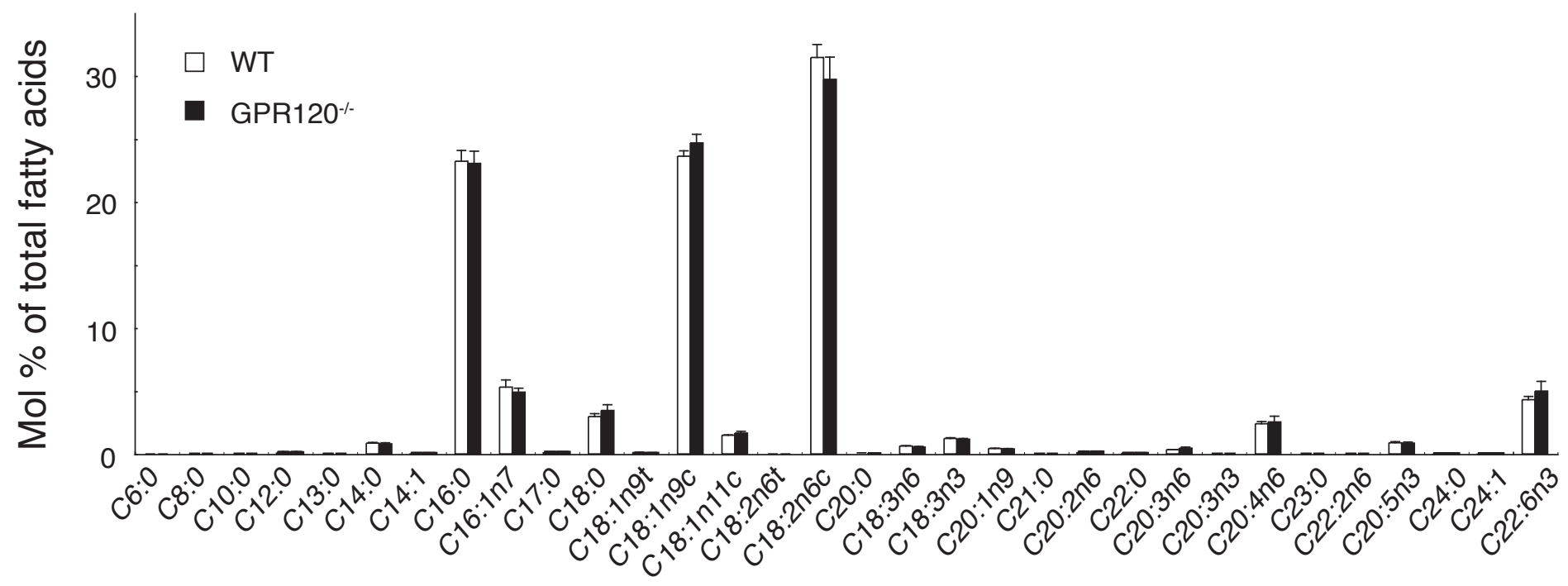

f

ND, Plasma Esterified, Fatty Acids

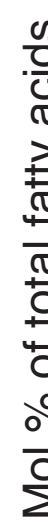

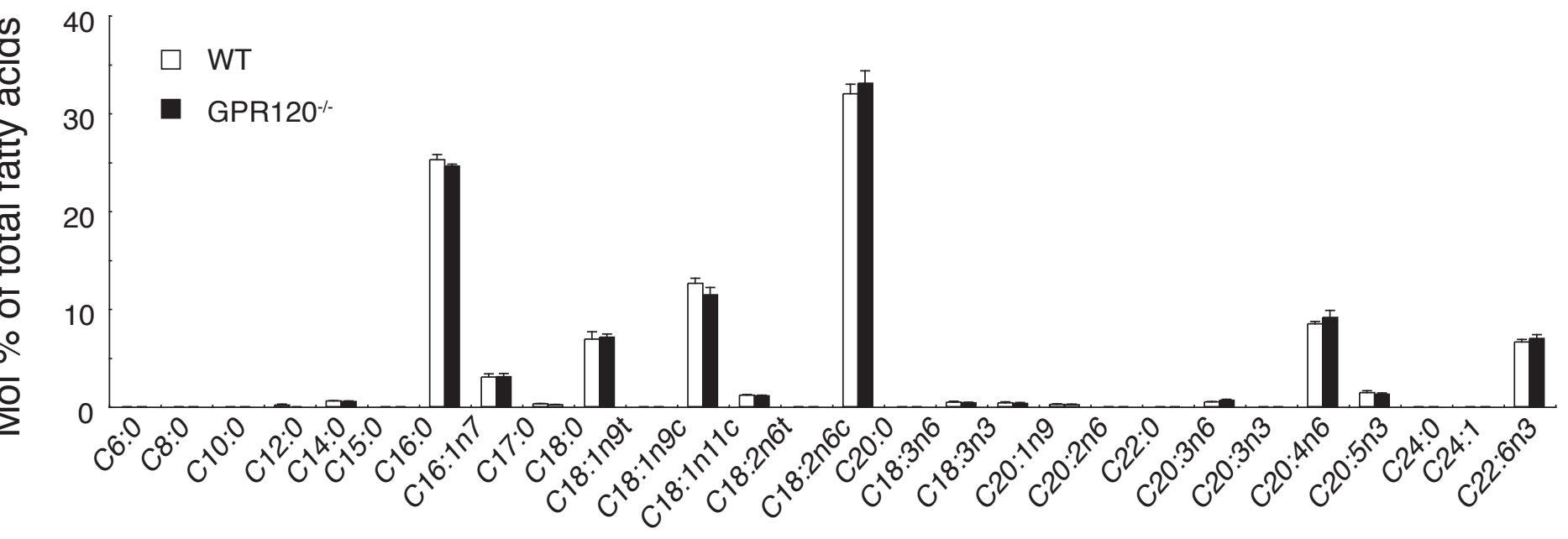


Adipose tissue, Nonesterified Fatty Acids

口 WT - GPR120-1-

g

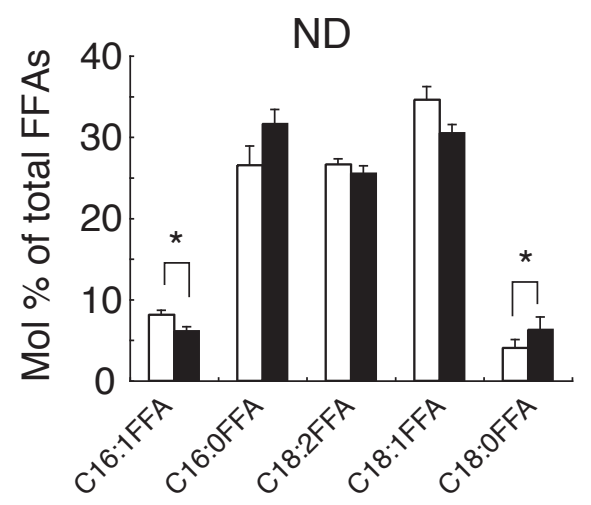

h

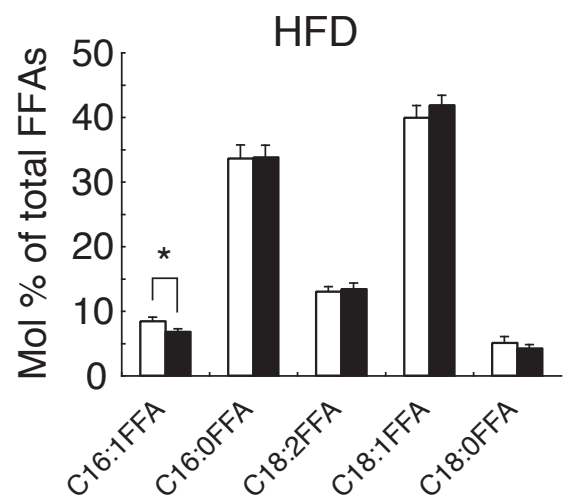

Liver, Nonesterified Fatty Acids
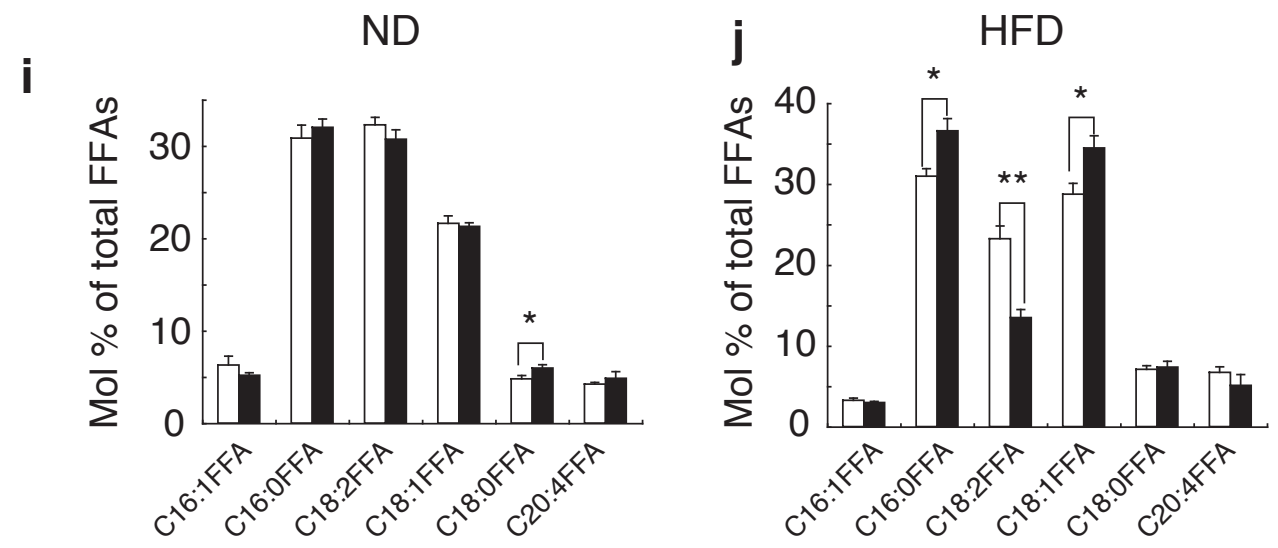

Plasma, Nonesterified Fatty Acids

$\mathbf{k}$

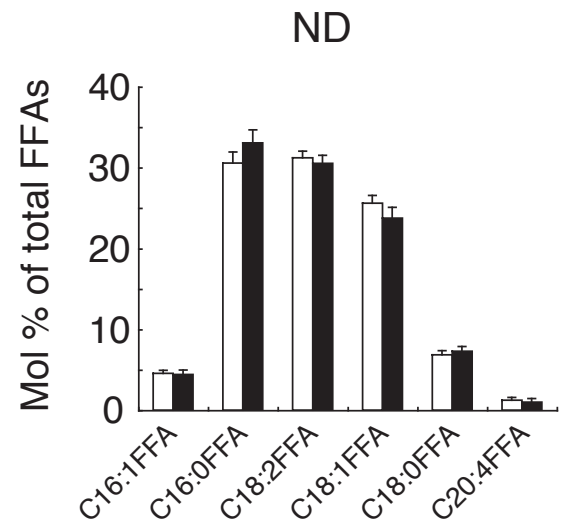

I HFD

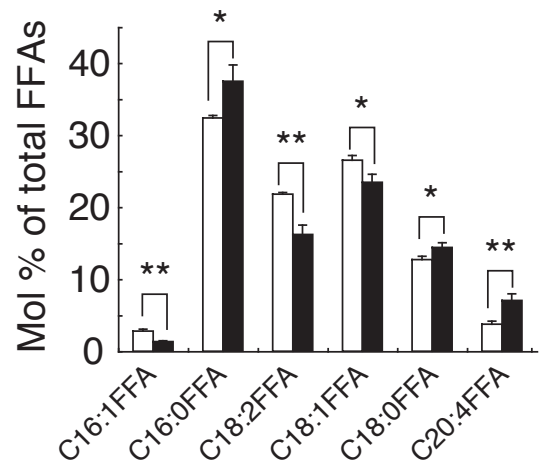

Supplementary Figure 6. Fatty acid composition in WT mice and GPR120-deficient mice.

Esterified fatty acid composition of (a) epididymal adipose tissue, (b) liver and (c) plasma in 16-week-old WT and GPR120-deficient mice fed HFD (n=6-7). Esterified fatty acid composition of (d) epididymal adipose tissue and (e) liver and (f) plasma from16-week-old WT and GPR120-deficient mice fed ND ( $\mathrm{n}=6-7)$. Non-esterified fatty acid composition of $(\mathbf{g}, \mathbf{h})$ adipose tissue, $(\mathbf{i}, \mathbf{j})$ liver and $(\mathbf{k}, \mathbf{l})$ plasma from 16-week-old WT and GPR120-deficient mice fed ND $(\mathbf{g}, \mathbf{i}, \mathbf{k})$ or HFD $(\mathbf{h}, \mathbf{j}, \mathbf{l})(\mathrm{n}=6-7)$. Data represent means \pm standard error. $* P<0.05$ and $* * P<0.01$ versus the corresponding WT value. $\boldsymbol{N D}$, normal diet; $\boldsymbol{H F D}$, high-fat diet; $\boldsymbol{W T}$, wild-type. 
a

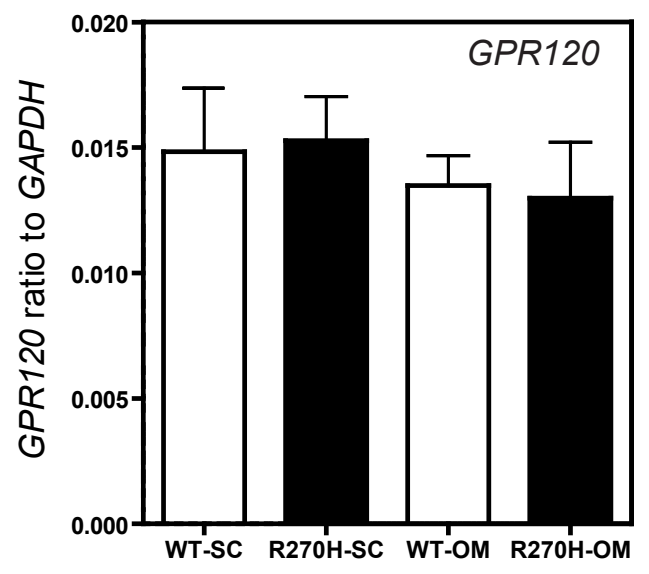

b
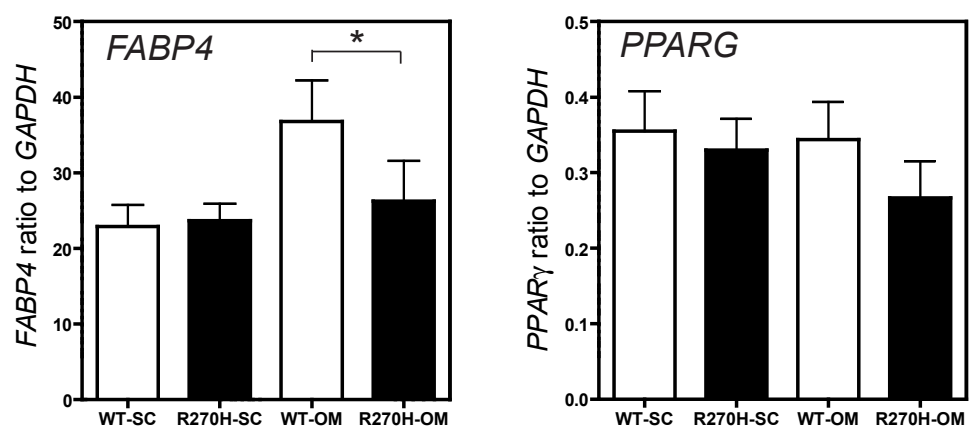

C
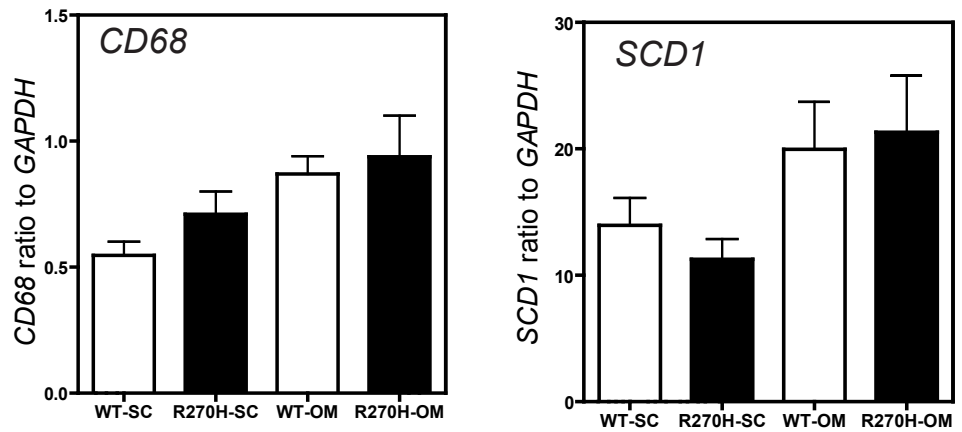

Supplementary Figure 7. GPR120, FABP4, PPARG, SCD1 and CD68 expression in human tissue samples according to $\mathbf{p . R 2 7 0 H}$ variant.

Expression studies have been performed in $10 \mathrm{WT}$ normoglycemic obese patients (WT; white) and 10 mutated for the p.R270H polymorphism (p.R270H; black) counterparts matched for age and gender by qRT-PCR. Data represent means \pm standard deviation (a) GPR120 mRNA levels in human SC and OM adipose tissues according to the p.R270H genotype. Mann-Whitney analysis demonstrated no significant difference between WT and mutated subjects. Wilcoxon analysis was performed to assess differences between both adipose depots, but no significant differences were detected. (b) FABP4 and PPARG mRNA levels in human SC and OM adipose tissues according to the p.R270H genotype. MannWhitney analysis demonstrated a significant difference between wild type and mutated subjects for FABP4 mRNA level which was lower in mutated subjects in omental compartment $(P=0.0433)$. Wilcoxon analysis was performed to assess differences between both adipose depots. FABP4 mRNA level was higher in OM tissue of WT subjects $(P=0.0039)$ but not significantly different in mutated subjects. No significant difference was detected between depots for PPARG. (c) CD68 and SCD1 mRNA levels in human SC and OM adipose tissues according to the p.R270H genotype. MannWhitney analysis demonstrated no significant difference between WT and mutated subjects in WAT. Wilcoxon analysis was performed to assess differences between both adipose depots. $C D 68$ was higher in OM tissue of WT $(P=0.002)$ and mutated $(P=0.0166)$ subjects. $S C D 1$ mRNA level was higher in OM tissue in mutated subjects $(P=0.0273)$ but did not reach statistical difference in WT subjects. $\boldsymbol{W T}$, wild-type; $\boldsymbol{S C}$, subcutaneous; $\boldsymbol{O M}$, omental (visceral). 